Review

\title{
Vinyl-ruthenium entities as markers for intramolecular electron transfer processes
}

\author{
Philipp Mücke ${ }^{a}$, Michael Linseis ${ }^{a}$, Stanislav Záliš ${ }^{b}$, Rainer F. Winter ${ }^{a, *}$ \\ anstitut für Anorganische Chemie, Universität Konstanz, Universitätsstraße 10, D-78453 Konstanz, Germany \\ ${ }^{\mathrm{b}}$ J. Heyrovský Institute of Physical Chemistry, v.v.i, Academy of Sciences of the Czech Republic, Dolejškova 3, 18223 Prague, Czech Republic
}

\section{Keywords:}

Ruthenium

Vinyl complexes

Electrochemistry

Spectroelectrochemistry

Mixed-valent

\section{A B S T R A C T}

The present account summarizes our work on mononuclear vinyl ruthenium complexes of the type $\mathrm{RuCl}\left(\mathrm{CH}=\mathrm{CHR}^{\prime}\right)(\mathrm{CO})\left(\mathrm{PR}_{3}\right)_{2} \mathrm{~L}$, divinyl bridged diruthenium complexes $\left\{\mathrm{RuCl}(\mathrm{CO})\left(\mathrm{PR}_{3}\right)_{2} \mathrm{~L}\right\}_{2}(\mu \mathrm{CH}=\mathrm{CH}$ bridge $\mathrm{CH}=\mathrm{CH}$ ) and on heterobinuclear systems where only one of the two redox active metal organic moieties is of the vinyl ruthenium type. The favourable electrochemical properties of the $\{\mathrm{RuCl}$ $(\mathrm{CO})\left(\mathrm{PR}_{3}\right)_{2} \mathrm{~L}(\mathrm{CH}=\mathrm{CH})$ tag and the various spectroscopic handles offered by that unit provide detailed insights into the charge and spin delocalization over the $\left\{\mathrm{MCl}(\mathrm{CO})\left(\mathrm{PR}_{3}\right)_{2} \mathrm{~L}\right\}$ and $\mathrm{CH}=\mathrm{CHR}^{\prime}$ constituents in their associated radical cations. They also offer a convenient means for measuring electronic coupling in the mixed valent radical cations of the homo and heterodinuclear vinyl bridged complexes and, under favourable circumstances, on the rate of intramolecular electron transfer between the individual redox sites. Aspects of this work include examples of complexes showing time dependent valence trap ping, complexes aimed at delineating the efficiencies of through space versus through bond pathways for electron delocalization, complexes where electrostatic effects on the redox splitting $\Delta E_{1 / 2}$ dominate over those from the resonance contribution and systems that exhibit extensive charge and spin delocalization between two dislike endgroups despite their intrinsically different re 


\section{Contents}

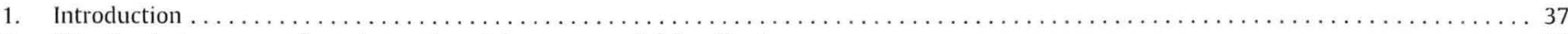

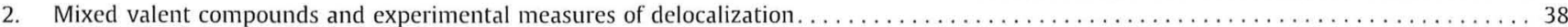

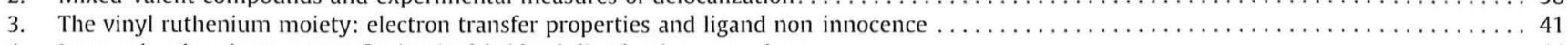

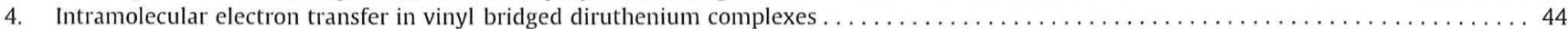

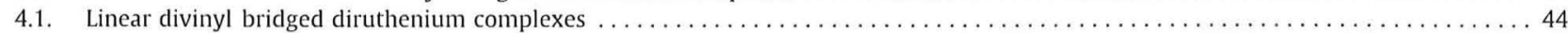

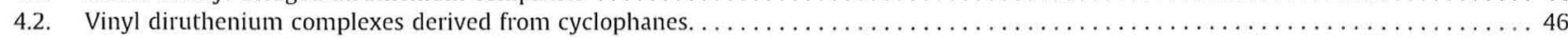

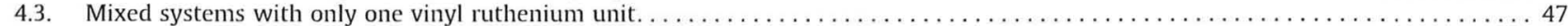

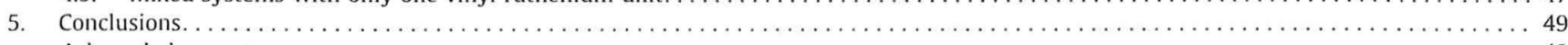

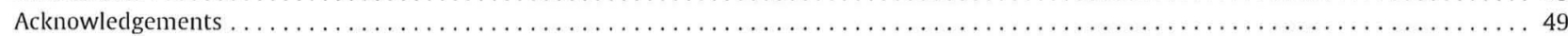

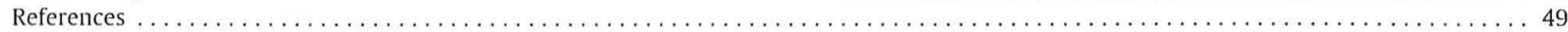

\section{Introduction}

Establishing and quantifying electronic interactions between interconnected redox active moieties in mixed valent (MV) systems continues to be a matter of considerable interest. Despite the tremendous amount of work devoted to that particular topic, research in this area is still driven by the urge to unravel the mech anisms and pathways by which intramolecular electron transfer in such systems occurs and to measure and control the degree of "electronic communication" between the individual redox sites. This is important from a fundamental and a practical point of view. Electron transfer, i.e. the exchange of an electron or a hole between two redox active molecules or between a molecule and an elec trode surface, is one of the two fundamental chemical processes. About $50 \%$ of all chemical reactions are believed to involve electron transfer at some point along the reaction path. On the other hand, insight from these studies also flows into the design of molecule based materials for modern electronics [1]. Mixed valent systems are a simple approach to molecular wires, circumventing the need for dealing with the intricacies of connecting individual molecules to electrodes of the macroscopic world and measuring potential/ current traces on such delicate arrays. While these issues certainly need to be addressed for any practical application, the fundamental information as to the intrinsic ability of individual molecules for that use can still be gleaned from such comparatively simple systems.

In this account we present an overview over some of our work on oligonuclear vinyl ruthenium complexes devoted to such issues. Radical cations derived from vinyl bridged diruthenium complexes differ from more "conventional" mixed valent systems in that they show a prevalent contribution of the organic vinyl constituent of these structures to the individual oxidation processes. In the fol lowing we will illustrate that these systems form extended metal organic $\pi$ systems and allow for measuring the charge and spin distribution between (i) the vinyl ligand and the remain ing metal coligand moiety on one hand and (ii) between individ ual vinyl ruthenium/coligand moieties on the other. In doing so, we will first briefly introduce the reader into the topic of mixed va lent compounds. Main emphasis will be on the issue of how to ob tain experimental information on the strength of the electronic interactions between individual redox active subunits in such sys tems (the so called "electronic communication") and on the time scale of intramolecular electron transfer. This will be followed by a brief discussion of the principal properties of vinyl ruthenium com plexes and their oxidized forms. Here we will detail why they are so good markers for charge and spin delocalization in extended 
multinuclear arrays. We will then present some examples of such systems that we consider as illustrative and instructional. These examples will include linear dinuclear systems as models of elec tron delocalization in one dimension, cyclophane derived systems as models of three dimensional delocalization through space and unsymmetrical systems with two different redox active moieties, only one of which is of vinyl ruthenium parentage.

\section{Mixed-valent compounds and experimental measures of delocalization}

Mixed valent (MV) compounds are defined as systems compris ing two or more identical (or, in terms of their intrinsic redox potentials, nearly so) redox active moieties in (formally) different oxidation states. In 1969, Creutz and Taube first published their seminal work on the pyrazine bridged bis(pentaamminerutheni $\mathrm{um})^{5+}$ ion (Chart 1) [2]. This so called Creutz Taube ion and related systems [3 5] soon gained truly paradigmatic importance for the development of this field. The greater simplicity of these dinuclear systems when compared to sets of separated redox pairs relies on the fact that electron transfer occurs in an intramolecular fashion, thus obliterating separate equilibria like that for the formation of encounter complexes. Moreover, electron transfer is a thermoneu tral process with no free energy change once the redox active moi eties have identical composition, such that no net thermodynamic driving force needs to be taken into account.

Owing to these circumstances, the Creutz Taube ion and its immediate relatives with bis(imine) bridging ligands other than pyrazine served as a blueprint for a large host of similar systems that share the same basic construction principle: there are always two (or more) identical or closely related redox active subunits joined by a common "spacer" or "bridge" (Fig. 1; for a stringent definition of these two terms see Ref. [6]). Variations on this gen eral theme come from the choice of the redox active moiety, which may be of inorganic, metal organic or purely organic nature, and of the bridge, which may be anything from unsaturated and fully

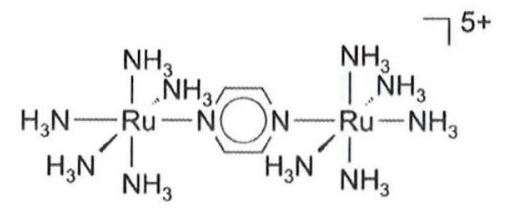

Chart 1. The Creutz-Taube ion.

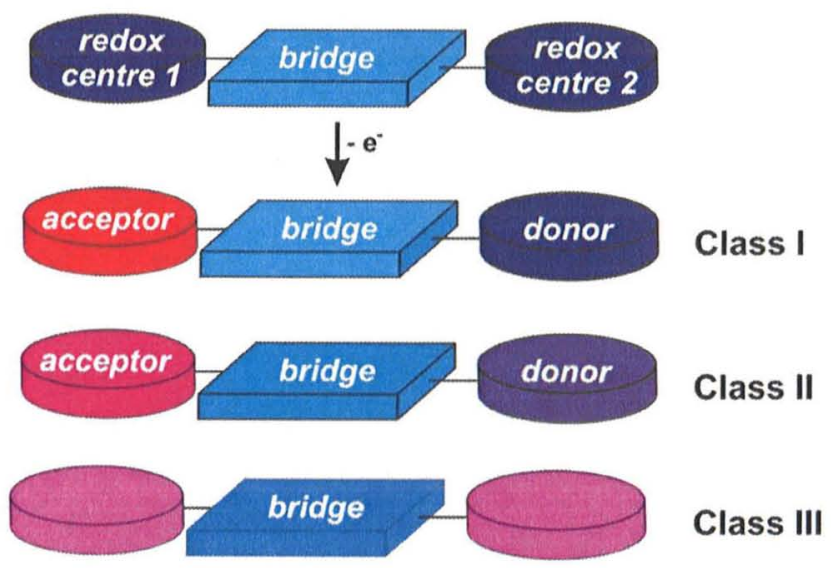

Fig. 1. Schematic representation of the electron distribution in mixed-valent systems of Classes I to III according to Robin and Day. conjugated to fully saturated. The interaction between the redox active endgroups and the common bridge is another important variable of such systems. Taken together, these alterations allow electronic interactions between the individual redox sites to be modified over several orders of magnitude, thus determining the properties of mixed valent systems in a very profound manner.

This is expressed in the Robin and Day classification scheme [7] where, based on the mutual interactions between the individual redox active subunits, mixed valent (MV) compounds are subdi vided into three different classes (Fig. 1). In MV compounds of Class I the bridge essentially behaves as an insulator. This means that the redox active moieties, albeit being of identical composi tion, differ strongly in their electron densities. Each one shows the same properties as would be observed in a similar system with just one of these moieties in its respective valence state (reduced or oxidized). For systems of Class II, the bridge allows for some de gree of electronic interactions between the conjoined local redox sites. This introduces new spectroscopic features that are not pres ent in either isovalent state, most importantly the so called "inter valence charge transfer" (IVCT) band (vide infra). In MV compounds of Class II, electronic coupling has the consequence of rendering the redox active termini electronically more similar but not to the extent of making them identical. There is at least one experimental method which indicates that they are electroni cally different, i.e. the rate of intramolecular electron transfer is slower than the timescale inherent to that experimental probe of the local electron densities. We will come back to this point in a la ter section of the present account. MV systems of Class III finally exhibit fully symmetrical charge and spin distributions over both local redox sites. In this scenario the redox sites acquire new (spec troscopic) properties that are connected with their fractional oxi dation states that differ from those in the bordering isovalent states. Here it is no longer possible to classify any of the redox sites as a donor or an acceptor. We have tried to symbolize these three different scenarios by the colour coding of Fig. 1 where the individ ual colours and shades represent the local electron (or spin) densi ties at the redox sites. More recently, borderline cases of Class II and III MV compounds have been identified as a class of their own [8] with unique properties such as the low energy cutoff of their IVCT band $[9,10]$. In such systems, the degree of the electronic coupling and "charge equilibration" is particularly sensitive to sol vent polarity and the solvation of the individual redox active sub units $[11,12]$.

Like for any other types of reactions, energy changes during intramolecular electron transfer processes can be described by vir tue of potential hypersurfaces. Here, the energy is plotted as a function of the so called electron transfer (ET) coordinate ( $X$ in Fig. 2). The typical shapes of such hypersurfaces for MV com pounds of Classes I and II are shown as the dotted and solid lines, respectively, in Fig. 2. One might wonder why a degenerate chem ical process such as intramolecular ET involves an energy barrier at all. The underlying reason is that ET between redox sites of even identical composition can only occur at a point where the two sites assume identical structures. This pertains to the internal bonding parameters (bond lengths, angles and dihedrals) as well as to the structure of the surrounding solvent shell. Bordering redox states $n^{+}$and $(n+1)^{+}$, however, usually differ in their intrinsic structures. Here, one only has to think of how ionic radii of metal ions, and, as a consequence, metal ligand bond lengths change with oxidation state. This means that ET can only occur from a structure that is distorted with respect to the ground state structures of both bor dering redox states. The ground state barrier to ET thus reflects the energy required to transform the ground state structures into the distorted, symmetrical one in which ET can occur. In the sim plest case the distortion rendering both sites structurally equiva lent is brought about by a single fundamental such as a 

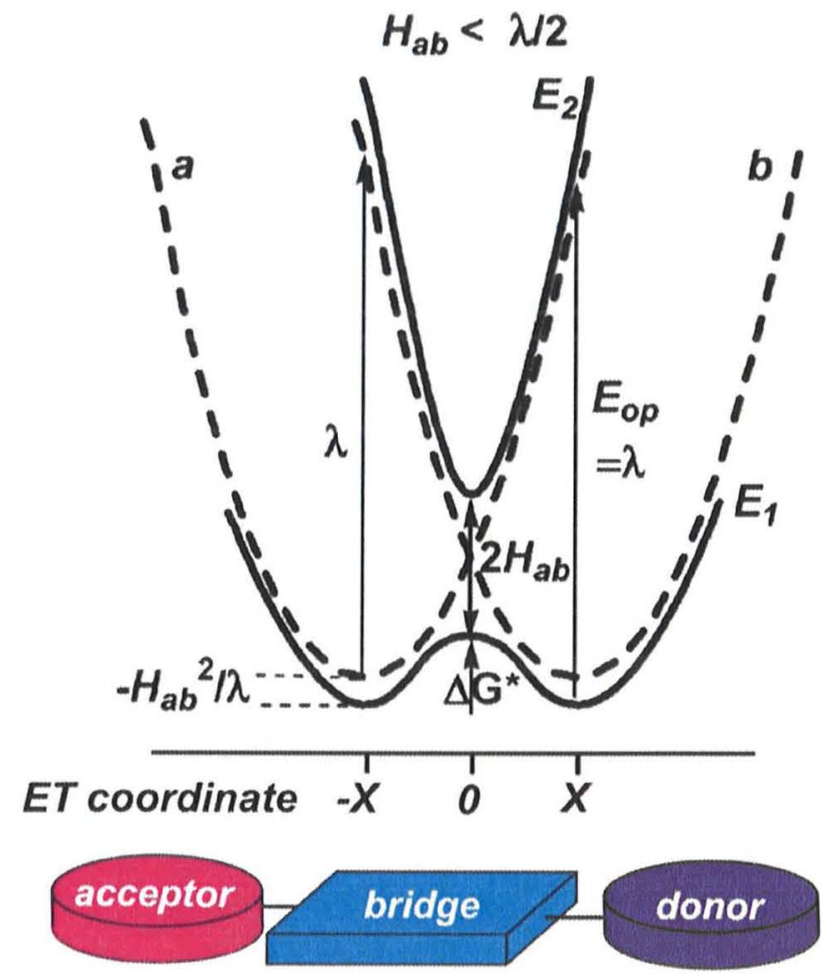

Fig. 2. Energy hypersurface of a mixed-valent compound of Class II (figure adapted from Ref. $|40|$ with permission).

symmetrical stretch, i.e. the site with higher oxidation state is ex panded from its equilibrium structure while the one with the low er oxidation state is contracted. For less symmetric systems the prerequisite structural changes involve more than just one such mode and are a more complex combination of several of them $\left[\begin{array}{ll}13 & 16\end{array}\right]$.

For MV compounds of Class II electronic coupling between the two redox sites leads to an avoided crossing of the individual dia batic hypersurfaces, which are usually assumed to have the hyper bolic shape of harmonic vibrations. This leads to a double minimum ground state, where the two minima at ET values of $+X$ and $X$ are symmetrically displaced from an ET coordinate va lue of 0 . This latter value denotes a fully symmetrical structure including the local redox sites and the bridge. The vertical displace ment of the antibonding state with respect to the bonding one at the ET coordinate value of 0 is twice the electron coupling matrix element $H_{A B}$. Intramolecular electron transfer can then occur in two ways: (i) as a thermally activated process where the system moves from one minimum of the lower adiabatic hypersurface to the other minimum by crossing the barrier separating them, and (ii) as a vertical electronic transition originating from one mini mum of the lower adiabatic ground state to the Franck Condon ex cited, antibonding state. From there, the excited electron may relax to the other ground state minimum. The latter event results in electron transfer from the former donor to the former acceptor site with a concomitant change of valencies. The underlying electronic transition is therefore dubbed as the "intervalence charge trans fer" or IVCT band. Not surprisingly, much useful information on the electronic coupling matrix element $H_{A B}$ can be gleaned from this band. The excitation energy equals the total reorganization en ergy $i$ which summarizes contributions from the reorganization of the internal structural parameters $\lambda_{\text {in }}$ and of the reorganization of the solvent shell surrounding the individual redox sites $\lambda_{\text {out }}$. Both need to adjust to the changing electron distributions upon intra molecular electron transfer.

MV systems of Robin and Day Class III have the minima of their ground and excited MV states at the ET coordinate value of 0 (see Fig. 3). This means that both states have fully symmetrical struc tures and symmetrical electron and spin density distributions. The electronic transition between these states is therefore called a charge resonance band, a term that was originally introduced to denote electronic bands that were observed for radical cations or anions of aromatic compounds in the presence of the neutral arene [17 19]. This transition does not induce a shift of charge density from one of the individual redox sites to the other but resembles more a transition within a delocalized chromophore.

How may one now obtain experimental information on the elec tronic coupling strength $H_{A B}$ and on the rate of intramolecular ET? Following a rule of thumb, electronic coupling within a MV system should lead to a splitting of half wave potentials for the consecu tive oxidations or reductions of the individual redox sites, and that splitting should increase as the electronic coupling increases. The rationale behind is that electronic coupling is expected to thermo dynamically stabilize the MV state with respect to the bordering isovalent states. This stabilization is measured by the compropor tionation constant $K_{\text {comp }}$ as given in Eq. (1). The relation between $K_{\text {comp }}$, the total free enthalpy $\Delta G$ of the comproportionation reac tion, and the splitting of half wave potentials, $\Delta E_{1 / 2}$, is given by Eq. (2). One has to bear in mind, however, that $\Delta E_{1 / 2}$ mirrors the free enthalpy changes upon the individual consecutive one elec tron transfer steps just as a redox potential mirrors the difference in total free enthalpies of the oxidized and the reduced redox cong eners. It is thus subject to several contributions besides the "reso nance" term $\Delta G_{\text {res }}$ which corresponds to the electronic coupling (see Eq. (3)) $[4,2022]$. First of all one has to consider electrostatic interactions $\Delta G_{\mathrm{e}}$. In the simplest case, that is, starting from a neu tral compound, the MV species is a singly charged radical cation or

$$
H_{a b}>\lambda / 2
$$
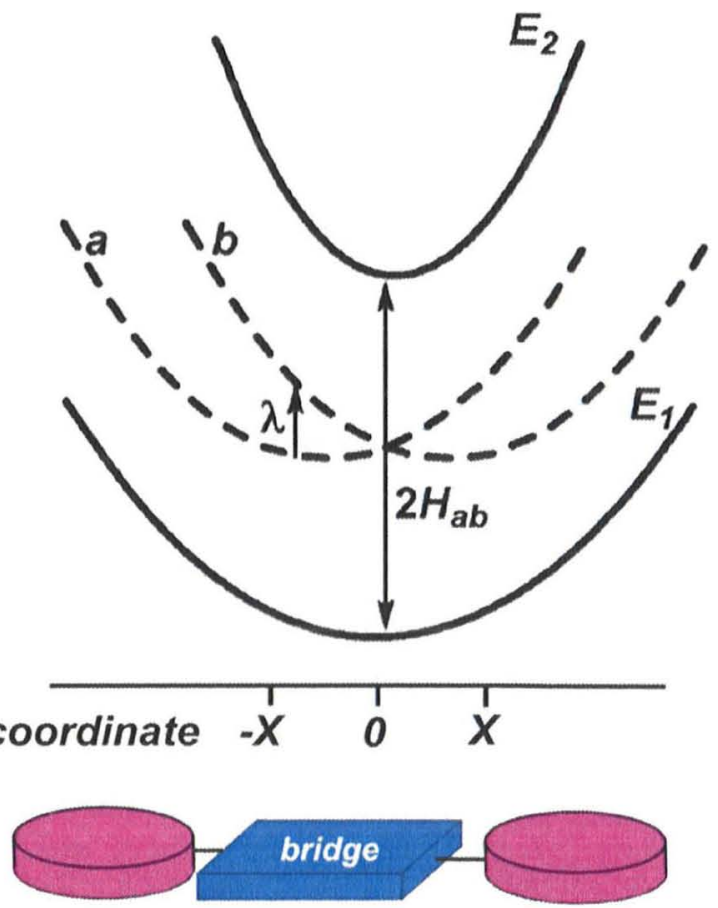

Fig. 3. Energy hypersurface of a mixed-valent compound of Class III (figure adapted from Ref. [40] with permission). 
anion, respectively. Removal (or addition) of another unit charge upon the second one electron transfer process thus generates a doubly charged system with one charge at each of the local redox sites. This second process then suffers a Coulomb penalty as one more charge is extracted from (or added to) an already positively (negatively) charged system. This effect alone by itself will lead to a splitting of half wave potentials if the spatial separation be tween the two redox sites is not so large that the one is electrically insulated from the other. Another contributor to the overall $\Delta G$ is the inductive term $\Delta G_{i}$. This term essentially accounts for the fact that electron transfer at one redox active subunit affects its bond ing to the bridge. This effect is then in turn transmitted through the bridge to the other redox active subunit, thus changing the local electron density at this site and hence its intrinsic redox potential. Further terms are the magnetic exchange term $\Delta G_{\mathrm{ex}}$ and the statis tical term $\Delta G_{\mathrm{s}}$. The latter accounts for the fact that a system with two identical, independent redox sites will display a potential sep aration of $2 \ln 2 R T / F=36 \mathrm{mV}$ at $T=298 \mathrm{~K}$ between the individual redox processes [23]. What follows from this discussion is that the resonance term $\Delta G_{\text {res }}$ is only one contributor amongst several. Moreover, $\Delta G_{\text {res }}$ is usually considerably smaller than the Coulom bic term $\Delta G_{\mathrm{e}}$, which often dominates the experimentally observed $\Delta G$ and $\Delta E_{1 / 2}$ values.

It has been shown that Coulombic interactions between adja cent redox sites do not only depend on the system itself but, to a large part, also on the experimental conditions of the electrochem ical experiment such as the solvent and the supporting electrolyte [24 26]. Two examples may illustrate this point. The first involves the stepwise oxidation of the bis(fulvene) dinickel complex 1 of Chart 2. Varying the anion of the supporting electrolyte from $\mathrm{Cl}$ to the very weakly nucleophilic $\left[\mathrm{B}\left(\mathrm{C}_{6} \mathrm{~F}_{5}\right)_{4}\right]$ increases $\Delta E_{1 / 2}$ from 273 to $744 \mathrm{mV}$ and $K_{\text {comp }}$ by 7 orders of magnitude. These changes mirror the different degrees of electrostatic shielding of the two re dox sites by their varying association with the counter ion of the supporting electrolyte [26].

$\mathrm{Red}-\mathrm{Red}+\mathrm{Ox}-\mathrm{Ox} \stackrel{K_{\text {comp }}}{\leftrightarrows} 2 \mathrm{Red}-\mathrm{Ox}$

$K_{\text {comp }} \frac{[\text { Red-Ox }]^{2}}{[\operatorname{Red}-\text { Red }][\mathrm{Ox}-\mathrm{Ox}]} \quad \exp \left\{\left(n F \Delta_{1 / 2}\right) /(R T)\right\}$

$\Delta G \quad \Delta G_{\mathrm{e}}+\Delta G_{\mathrm{i}}+\Delta G_{\mathrm{ex}}+\Delta G_{\mathrm{s}}+\Delta G_{\mathrm{res}}$
The second example is about the stepwise dithiolene based reductions of the nickel complex $\left(\mathrm{Fc}_{2} \mathrm{C}_{2} \mathrm{~S}_{2}\right)_{2} \mathrm{Ni}, 2$ of Chart 2. Here, the splitting between individual reduction potentials strongly de pends on the solvent and the cation of the supporting electrolyte. Thus, replacing the bulky, weakly associating $\mathrm{NBu}_{4}{ }^{+}$cation of the $\mathrm{NBu}_{4}{ }^{+}\left[\mathrm{B}\left\{\mathrm{C}_{6} \mathrm{H}_{3}\left(\mathrm{CF}_{3}\right)_{2}\right\}_{4}\right]$ salt by $\mathrm{Na}^{+}$in $\mathrm{CH}_{2} \mathrm{Cl}_{2}$ diminishes $\Delta E_{1 / 2}$ from $770 \mathrm{mV}$, i.e. a value that one would safely take as indicating fully delocalized Class III behaviour of the MV radical anion, to the statistical limit of $40 \mathrm{mV}$ that one would expect in the absence of any electronic coupling [26]. These examples show, how exper imental $\Delta E_{1 / 2}$ values may be governed by electrostatic interactions. This renders $\Delta E_{1 / 2}$ a rather qualitative indicator for electronic cou pling in MV systems, even when data on closely related sets of compounds obtained under closely similar conditions of solvent, supporting electrolyte, analyte concentration and temperature are compared, and better measures for this quantity are warranted. Albeit there are several examples where the electronic coupling $H_{A B}$ and $\Delta E_{1 / 2}$ go in parallel [9,27 30], there are also some where no such correlation exists [31]. One such example will be detailed in a later section of this account.

On discussing the potential hypersurfaces for ET reactions we have already pointed out that intramolecular ET in MV systems of Class II can be induced by irradiation into the corresponding IVCT band. As a matter of fact, this band offers perhaps the most straightforward access to the electron coupling matrix element $H_{A B}$. For moderately coupled mixed valent systems of Class II, $H_{A B}$ can be calculated from Eq. (4) following the theoretical framework of Hush, i.e. only one excited state is taken into ac count and all potential wells are assumed to be harmonic [32,33]. In Eq. (4), $v_{\max }, \Delta v, \varepsilon_{\max }$ and $r_{A B}$ denote the energy (in $\mathrm{cm}^{1}$ ) at the band maximum of the IVCT transition, the band width at half height (in $\mathrm{cm}^{1}$ ), the molar extinction coefficient at the band maximum in $1 \mathrm{~mol}^{1} \mathrm{~cm}^{1}$ and the charge transfer distance, i.e. the spatial distance over which the electron moves during the IVCT excitation. The treatment of MV systems of Class III is even simpler: Here, $H_{A B}$ is just half the energy at the maxi mum of the charge resonance band.

$$
H_{A B} \quad 0.0205\left(\tilde{v}_{\max } \cdot \Delta \tilde{v} \cdot \varepsilon_{\max }\right)^{1 / 2} / r_{A B}
$$

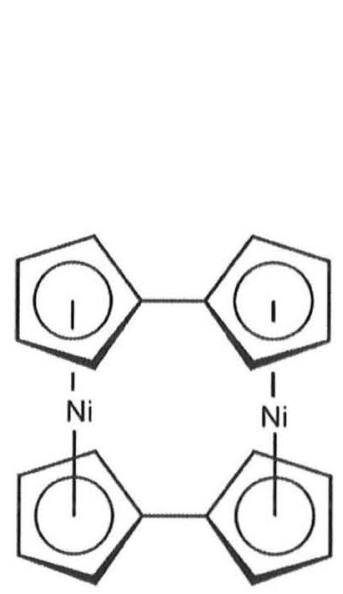

1

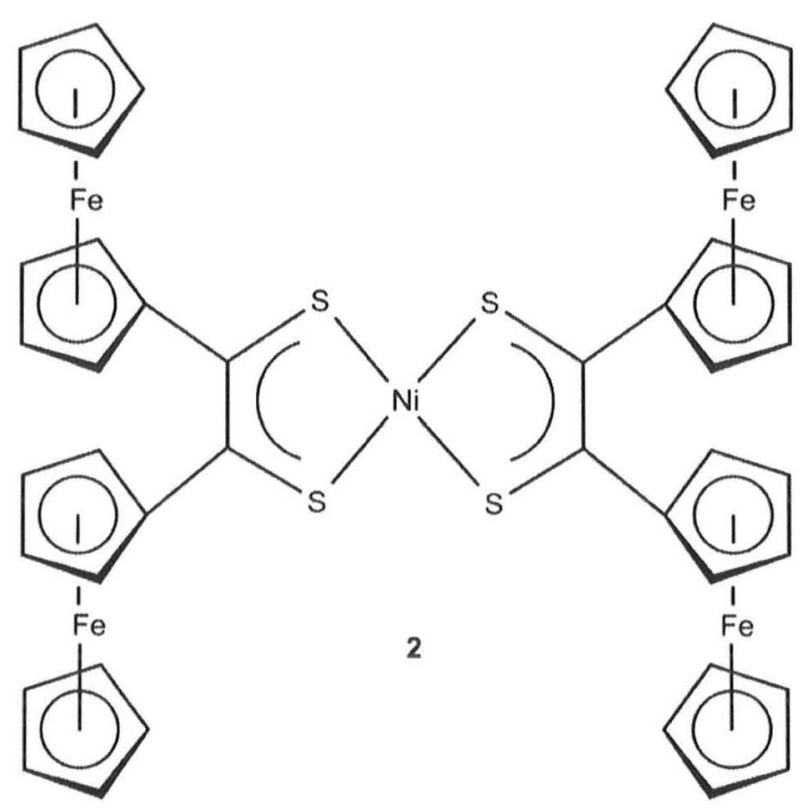

Chart 2. 
The calculation of $H_{A B}$ of Class II systems from IVCT band parameters is also not wholly without possible problems and pit falls. One source of uncertainty pertains to the charge transfer dis tance $r_{A B}$. This parameter is often taken as the spatial separation between the centres of the bridged redox sites, which, in coordina tion compounds, are assumed to be the metal atoms. Such a proce dure may, however, grossly overestimate $r_{A B}$ with respect to the true electron transfer distance and, consequently, underestimate $H_{A B}$, particularly when the relevant "redox orbital" that is primar ily involved in electron transfer delocalizes onto the bridge [34 38]. Unfortunately, the true electron transfer distance is noto riously difficult to come by experimentally, with electroabsorption (Stark) spectroscopy as about the only means. "All optical" and quantum chemical approaches to determine $r_{A B}$ have also been re ported but are anything but simple. In the case of quantum chem ical approaches, the result strongly depends on the functional employed in the calculations [11,39 45].

Above that, the identification of the IVCT band as such is some times neither unambiguous nor trivial. An IVCT band usually oc curs in the low energy part of the visible region or in the near infrared (NIR) and is "endemic" of the MV state but absent in the neighbouring isovalent ones. The specific appearance of a low en ergy electronic transition in the MV state is often taken as suffi cient evidence for its assignment as such. Indeed, the specificity criterion usually distinguishes an IVCT band from $\mathrm{d} d$ bands that may arise from abstracting an electron from the $d$ manifold of a transition metal based redox site: the isovalent species resulting from electron transfer from the second of these sites also features such d $\mathrm{d}$ bands. The same applies to ligand to metal charge trans fer (LMCT) bands of metal oxidized forms or metal to ligand charge transfer (MLCT) bands of metal reduced forms since both types of transitions will occur in systems where either a single or both metal endgroups have undergone ET. It is, however, still pos sible, that singly oxidized radical cations of MV complexes display low energy metal to ligand charge transfer (MLCT) bands that correspond to the transfer of charge from the remaining reduced site to the now less electron rich bridging ligand or that radical an ions of such systems display low energy ligand to metal charge transfer (LMCT) bands from the bridging ligand, which has gained electron density in the reduction process, to the remaining oxi dized site. The probability of such transitions increases as the bridge becomes more and more involved in the ET process. In the case of more substantial or even dominating bridge contribution to the SOMO of the MV system, one may even observe low energy bands that resemble those expected for a bridge based radical cat ion or anion. Bands of such origin may also be specific to the MV state but should not be mistaken as IVCT transitions. We will dis cuss several such examples as we go along.

An elegant approach to finding out which class a certain MV system should be assigned to or to elucidating the rate at which intramolecular ET occurs is to furnish the redox active moieties or the bridge with spectroscopic tags which are indicative of the local charge or spin densities (which need not be the same) at these sites. Useful spectroscopic techniques include EPR spec troscopy, where information on the spin density distribution is encoded in the hyperfine splitting pattern to other nuclei bearing a nuclear spin, Moessbauer spectroscopy, where information on the valence state can be derived from the isotropic shift and the quadrupole splitting, or IR spectroscopy, where local vibrators whose force constants or band patterns are sensitive to the charge density on the redox active moiety or to the symmetry and the electron distribution within the bridge are required. Such role can be played by $\mathrm{CO}, \mathrm{NO}, \mathrm{C} \equiv \mathrm{N}$ or $\mathrm{C} \equiv \mathrm{C}$ stretches of redox ac tive moieties bearing carbonyl, nitrosyl, nitrile/isonitrile or alky nyl tags. With respect to these spectroscopic techniques one should note that each of them is associated with its own inherent time constant [46]. While the timescales of EPR (ca. $10^{8} \mathrm{~s}$ ) and of Moessbauer spectroscopy (ca. $10{ }^{9} \mathrm{~s}$ ) are rather similar, vibra tional motions occur at much faster rate of $10^{11}$ to $10^{12} \mathrm{~s}$. IR spectroscopy is thus the method of choice for obtaining informa tion about intrinsic (de)localization within a MV system [47]. One may envision a situation where a MV system appears to be delo calized by the EPR or Moessbauer techniques but localized on the faster IR timescale. Such behaviour has been observed and has been denoted as "time dependent valence trapping" (or detrap ping) $[28,48]$. It allows to bracket the time domain at which intra molecular ET occurs.

\section{The vinyl ruthenium moiety: electron transfer properties and ligand non-innocence}

Chart 3 schematically shows the types of vinyl ruthenium moi eties that we have employed in our work as markers for intramo lecular ET. The rather low and well accessible oxidation potentials, a stability of the various oxidized forms that allows for their (elec tro)chemical generation and spectroscopic characterization, the EPR activity of most of the aryl substituted vinyl complexes (except for those with acceptor substituents on the arene core) and the presence of one carbonyl ligand at each vinyl ruthenium site are factors that contribute to their great utility for this purpose. CO stretches of carbonyl ligands offer a highly convenient label for measuring the metal contribution to the relevant "redox orbital" and for obtaining information about the electronic equivalence or inequivalence of the individual vinyl ruthenium moieties and the ground state delocalization in the MV state of a complex compris ing more than one such entity.

The synthesis of the vinyl ruthenium complexes of Chart 3 is simple and straightforward and involves the regio and stereospe cific insertion of a terminal alkyne into the $\mathrm{Ru} \mathrm{H}$ bond of a hydride complex $\mathrm{RuClH}(\mathrm{CO})\left(\mathrm{PR}_{3}\right)_{n}$ where $n=3$ for $\mathrm{PAr}_{3}$ or 2 for bulky, strongly electron donating alkyl phosphines such as $\mathrm{P}^{i} \mathrm{Pr}_{3}, \mathrm{P}($ cyclo hexyl) $)_{3}$ or $\mathrm{PPh}^{t} \mathrm{Bu}_{2}$ as the crucial step [49 54]. In this so called hydroruthenation any terminal alkyne will work unless it carries too bulky substituents to allow for formation of the primary alkyne associate preceding the insertion step as it is the case for ${ }^{t} \mathrm{BuC} \equiv \mathrm{CH}$ or $\left(\mathrm{CF}_{3}\right)_{3} \mathrm{C}=\mathrm{CH}\left[\begin{array}{ll}55 & 58\end{array}\right]$. Upon alkyne insertion, the former hydride is transferred to the $\beta$ carbon atom of the vinyl ligand and ends up at the same side as the ruthenium atom on $C_{\alpha}$. This means, that the $\mathrm{Ru} \mathrm{CH}=\mathrm{CHR}$ unit inevitably has trans disposition of the $\mathrm{R}$ and the $\mathrm{Ru}$ "substituents" at the $\mathrm{C}=\mathrm{C}$ double bond.

Starting from tris(triarylphosphine) hydride precursors, alkyne insertion usually generates a mixture of five and six coordinated complexes with three or only two phosphine ligands and an empty coordination site trans to the vinyl ligand. Binding of the third phosphine ligand is rather weak [59] such that this ligand can be removed by extraction into a suitable solvent or by precipitation of the five coordinated complexes from hexanes/methanol mix tures. The five coordinated 16 valence electron vinyl complexes thus obtained may accept a suitable donor ligand such as a pyri dine, $\mathrm{CO}$, an isonitrile, an amine, a nitrile and so on (Scheme 1). The easy substitution of the chloro ligand for another anionic mono or bidentate ligand offers additional possibilities as to an a posteriori modification of the metal coordination sphere.

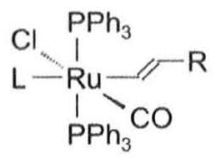<smiles></smiles><smiles>[R]C=C[Pb](Cl)([Pb])[Pb]</smiles>

Chart 3. 


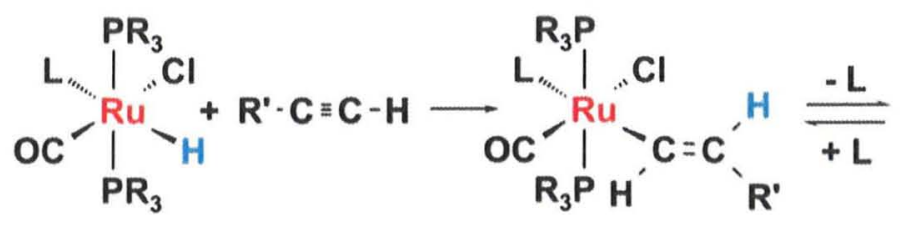<smiles>[R]C=C(C=O)[R]([R5])([R5])Cl</smiles>

Scheme 1.

The labile coordination of the third phosphine ligand in tris(tri arylphosphine) vinyl ruthenium complexes is a consequence of the strong $\sigma$ trans influence of the vinyl ligand and of steric crowding due to the meridional arrangement of three bulky phosphine li gands. It is thus more pronounced in complexes with bulky phos phines than in those with sterically less demanding ones like $\mathrm{PMe}_{3}$ or $\mathrm{PEt}_{3}$. Complexes $\mathrm{RuCl}\left(2\right.$ pyrenylvinyl)(CO) $\left(\mathrm{PPh}_{3}\right)_{3}$ (d Ru P cis to vinyl range from $2.402(1)$ to $2.440(1) \AA$ for the two independent molecules of the unit cell while d Ru P trans to vinyl amounts to 2.585(1) or 2.564(1) Å) (Fig. 4) [60] and $\left\{\mathrm{RuCl}(\mathrm{CO})\left(\mathrm{PMe}_{3}\right)_{3}\right\}_{2}(\mu$ $\mathrm{CH}=\mathrm{CH}$ Aryl $\mathrm{CH}=\mathrm{CH}$ ), where the Ru P bond trans to the vinyl li gand is by $412 \mathrm{pm}$ longer than those cis to the vinyl ligand [61], may serve to illustrate this point. Five coordinated vinyl com plexes assume a square pyramidal structure with the vinyl ligand, as the one with the largest $\sigma$ trans influence of all ligands present, in the apical position [52]. The vinyl ruthenium entity is planar and parallel to the $\mathrm{ClRu}(\mathrm{CO})$ vector. In the solid state, the vinyl ligand is usually oriented towards the carbonyl ligand owing to secondary stabilizing $\pi$ donor $/ \pi$ acceptor interactions [62]. In aryl substi tuted vinyl complexes, the vinyl ruthenium moiety is more or less coplanar to the respective aryl substituent; torsional angles Ru $\mathrm{CH}=\mathrm{CH}$ C(Aryl) typically range from about $5^{\circ}$ to $20^{\circ}$. This already signals extended conjugation within the entire vinyl ruthenium moiety.

Mononuclear vinyl ruthenium complexes $\mathrm{RuCl}\left(\mathrm{CH}=\mathrm{CHR}^{\prime}\right)(\mathrm{CO})$ $\left(\mathrm{PR}_{3}\right)_{2} \mathrm{~L}\left(\mathrm{R}=\mathrm{Ph}, \mathrm{L}=4\right.$ substituted pyridine, $\mathrm{R}={ }^{i} \mathrm{Pr}, \mathrm{L}=$ none $)$ may now serve to introduce the reader to the basic properties of this class of compounds and to detail some of the points raised above. Electrochemical oxidation of these systems occurs as a chemically and electrochemically mostly reversible one electron process [58]. Exceptions are complexes with electron withdrawing substituents

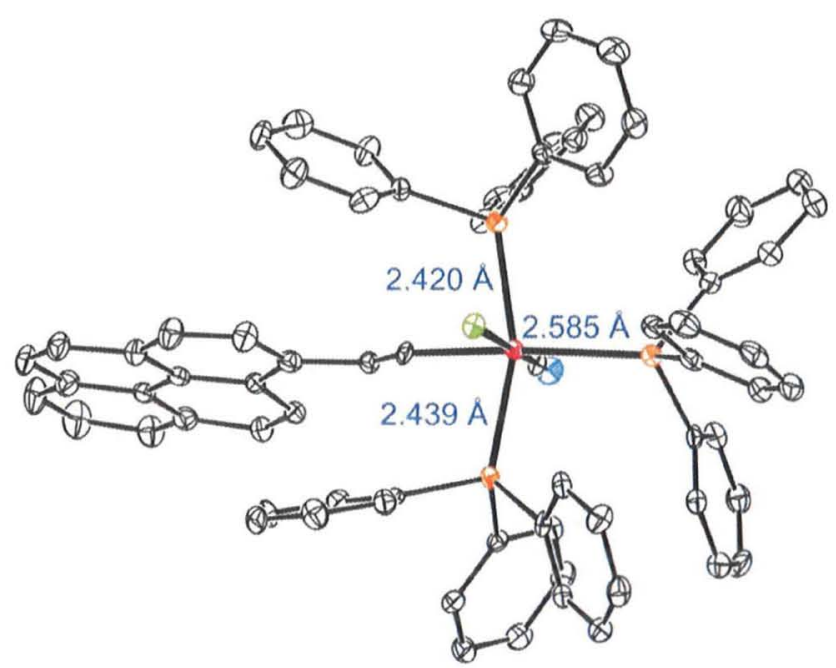

Fig. 4. Crystallographic structure of $\mathrm{RuCl}(\mathrm{CH}=\mathrm{CH}-2$-pyrenyl $)(\mathrm{CO})\left(\mathrm{PPh}_{3}\right)_{3}$ with $\mathrm{Ru}-\mathrm{P}$ bond lengths (only one of the two crystallographically independent molecules is shown).
$\mathrm{R}^{\prime}$ on the alkenyl ligand as in $\mathrm{CH}=\mathrm{CHCF}_{3}$ or $\mathrm{CH}=\mathrm{CH} \mathrm{C}_{6} \mathrm{H}_{4} \mathrm{NO}_{2} 4$ where partial decomposition of the associated radical cations al ready occurs on the voltammetric timescale. Conversion to 18 va lence electron systems, e.g. by chloride replacement with carboxylates, generally helps to increase chemical reversibility of less reversible systems. Redox potentials strongly depend on the vinyl substituent as it is shown by the series of 4 substituted styryl complexes $\mathrm{RuCl}\left(\mathrm{CH}=\mathrm{CH} \mathrm{C}_{6} \mathrm{H}_{4} \mathrm{X} 4\right)(\mathrm{CO})\left(\mathrm{PMe}_{3}\right)_{3} \quad$ [63] and $\mathrm{RuCl}\left(\mathrm{CH}=\mathrm{CH} \mathrm{C}_{6} \mathrm{H}_{4} \mathrm{X} 4\right)(\mathrm{CO})\left(\mathrm{P}^{i} \mathrm{Pr}_{3}\right)_{2}$ [64], where shifts of 710 or $660 \mathrm{mV}$ have been observed between $X=\mathrm{NMe}_{2}$ and $X=\mathrm{NO}_{2}$ as the two extremes. Complexes with donor substituted or more ex tended aryl substituents like $\mathrm{CH}=\mathrm{CH} \mathrm{C}_{6} \mathrm{H}_{4} \mathrm{NMe}_{2} 4$ or $\mathrm{CH}=\mathrm{CH} 2$ pyrenyl may also undergo a second reversible redox process at well accessible potentials. In these cases, the dioxidized dications can also be generated and investigated (Fig. 5). For simple alkenyl and non donor substituted styryl complexes the second oxidation occurs as a chemically irreversible process at a significantly higher potential or, for acceptor substituted representatives, even outside the anodic limit of the $\mathrm{NBu}_{4} \mathrm{PF}_{6} / \mathrm{CH}_{2} \mathrm{Cl}_{2}$ supporting electrolyte.

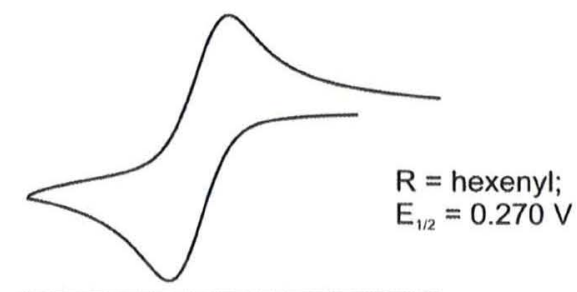

$\begin{array}{lllllllll}0.6 & 0.5 & 0.4 & 0.3 & 0.2 & 0.1 & 0.0 & -0.1 & -0.2 \mathrm{~V}\end{array}$

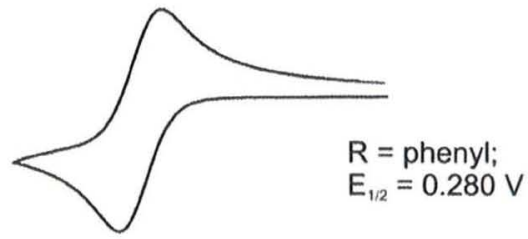

$\begin{array}{lllllllll}0.6 & 0.5 & 0.4 & 0.3 & 0.2 & 0.1 & 0.0 & -0.1 & -0.2 \mathrm{~V}\end{array}$

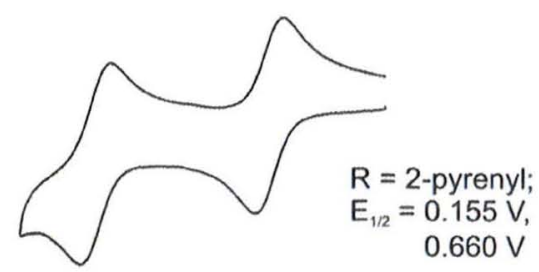

$\begin{array}{llllllll}1.0 & 0.8 & 0.6 & 0.4 & 0.2 & 0.0 & -0.2 \mathrm{~V}\end{array}$

Fig. 5. Voltammograms $\left(v=0.1 \mathrm{~V} / \mathrm{s}, 0.2 \mathrm{M} \mathrm{NBu}_{4} \mathrm{PF}_{6}\right.$ in $\left.\mathrm{CH}_{2} \mathrm{Cl}_{2}, \mathrm{rt}\right)$ of complexes $\mathrm{RuCl}(\mathrm{CH}=\mathrm{CH}-\mathrm{R})(\mathrm{CO})\left(\mathrm{P}^{i} \mathrm{Pr}_{3}\right)_{2}$. 
The radical cations of aryl substituted complexes lacking a strong acceptor substituent are EPR active in fluid solution with isotropic $g$ values of about 2.01 2.02. EPR spectra of $\mathrm{PiPr}_{3}$ com plexes often display resolved hyperfine splittings to the ${ }^{31} \mathrm{P}$ and the ${ }^{99 / 101} \mathrm{Ru}$ nuclei. Set against the backdrop of the rapid spin lat tice relaxation in "true" $\mathrm{Ru}^{\mathrm{III}}$ paramagnetic species, necessitating low temperatures of about $100 \mathrm{~K}$ and frozen solvent matrices in or der to detect their EPR signatures, the room temperature EPR activity of those systems comes as quite a surprise. There is an other striking difference between the EPR spectra of more "conven tional" organometallic $\mathrm{Ru}^{\mathrm{III}}$ based and oxidized arylvinyl ruthenium complexes: the $g$ values of the former differ more sub stantially from that of the free electron $\left(g_{e}=2.0023\right)$ and they usu ally exhibit rhombic or axial $g$ tensors with anisotropies $\Delta g$ in the range of 0.3 to $>1.0[65,66]$. In contrast, oxidized vinyl ruthenium complexes $\left[\mathrm{RuCl}(\mathrm{CH}=\mathrm{CH} \text { Aryl })(\mathrm{CO})\left(\mathrm{PR}_{3}\right)_{2} \mathrm{~L}\right]^{+}$(which were also $\mathrm{Ru}^{\prime \prime \prime}$ species if the oxidation was metal based) may display no $g$ anisot ropy at all or a significantly smaller $g$ tensor splitting in frozen solution and in the solid state. Thus, $\Delta g$ usually amounts to less than 0.03 in complexes bearing unsubstituted aryl substituents and scales with the Hammett parameter of the para substituent in 4 substituted styryl complexes [64]. Those observations desig nate oxidized alkenyl complexes as metal stabilized organic radi cals. One might expect that ${ }^{31} \mathrm{P}$ and ${ }^{99 / 101} \mathrm{Ru}$ hyperfine coupling constants for oxidized vinyl ruthenium complexes provide an indicative handle for estimating the metal contribution to the SOMO. Unfortunately, there seem to be no such data for genuine paramagnetic Ru ${ }^{\text {III }}$ species to compare with. Based on these results, radical cations derived from vinyl ruthenium complexes are even more "organic" than those derived from oxidized 4 substituted phenylethynyl ruthenium complexes trans $\left[\mathrm{Cl}(\text { dppe })_{2} \mathrm{Ru} \mathrm{C}=\mathrm{C}\right.$ $\left.\mathrm{C}_{6} \mathrm{H}_{4} \mathrm{X} \mathrm{4}\right]^{+}$and $\left[\mathrm{Cp}(\mathrm{dppe}) \mathrm{Ru} \mathrm{C} \equiv \mathrm{C}_{6} \mathrm{H}_{4} \times{ }^{4}\right]^{+}[66,67]$, where the unsaturated organic ligand significantly contributes to the SOMO. It is therefore only fair to denote the alkenyl ligands in these com plexes as "non innocent", meaning that they actively participate in the redox process and generate considerable ambiguity about the metal oxidation state $[68,69]$.

Additional experimental evidence for strong vinyl ligand partic ipation to the SOMO comes from the observation of vibrationally structured bands in the low energy region of the visible or in the NIR for their radical cations (for an example see Fig. 6). Vibrational splittings are due to coupling of $\mathrm{C}=\mathrm{C}$ stretching and $\mathrm{C}=\mathrm{CH}$ bending modes to the electronic transition(s). Both is highly characteristic of unsaturated, conjugated organic radicals, but not of $\mathrm{Ru}^{\mathrm{III}}$ para magnetic species.

The synergistic nature of the metal carbonyl bond makes the energy of the $\mathrm{CO}$ stretch and its shift upon a redox process sensi

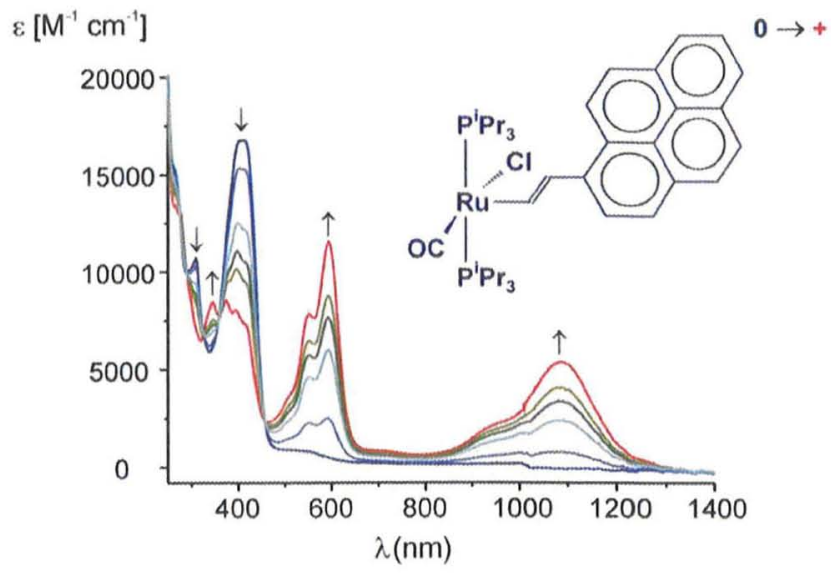

Fig. 6. Spectroscopic changes during electrochemical oxidation of $\mathrm{RuCl}(\mathrm{CH}=\mathrm{CH}-2$ pyrenyl)(CO)( $\left(\mathrm{P}^{i} \mathrm{Pr}_{3}\right)_{2}$ to its radical cation $\left(0.2 \mathrm{M} \mathrm{NBu}_{4} \mathrm{PF}_{6}\right.$ in $\left.1,2-\mathrm{C}_{2} \mathrm{H}_{4} \mathrm{Cl}_{2}, \mathrm{rt}\right)$.

tive measures of the local electron density at the metal and its change upon addition or removal of an electron. A metal centred oxidation depletes the metal atom of $\mathrm{d}$ electron density and thus decreases backbonding to the $\pi^{*}$ acceptor orbitals of the CO ligand. As a consequence, the $\mathrm{CO}$ force constant increases as lesser elec tron density flows into $\mathrm{CO}$ antibonding orbitals. The result is a siz able blue shift of $v(\mathrm{CO})$ by about $120150 \mathrm{~cm}^{1}$ as it is observed, for example, in pairs of complexes Ru(CO $)_{3}\left(\mathrm{PR}_{3}\right)_{2}{ }^{0 /+}[70]$.

We have prepared and investigated a series of substituted vinyl complexes that differ with respect to the spatial extension of the vinyl ligand's $\pi$ system and observed a systematic decrease of the oxidation induced blue shift of $v(\mathrm{CO})$ with increasing conjuga tion length of that ligand (see Fig. 7) [60,64]. The CO band shift of complexes with even simple alkenyl ligands is only about half of that expected for a metal centred oxidation. We presently have no data that indicate to what extent the mutual cis disposition of the carbonyl and the vinyl ligands contributes to the small magni tude of this shift. We note, however, that quantum chemical calcu lations on somewhat simplified model systems $\left(\mathrm{P}^{\mathrm{i}} \mathrm{Pr}_{3}\right.$ ligands modelled as $\mathrm{PMe}_{3}$ ), while nicely reproducing our experimental observations including the qualitative magnitude of the $\mathrm{CO}$ band shift, also indicate a ca. 50\% contribution of the hexenyl ligand to the HOMO of the reduced and to the SOMO of the oxidized form. Vinyl ligand contribution to these orbitals steadily increases as the butyl substituent is replaced by phenyl and by 2 pyrenyl. Con trol calculations of the exact model of $\mathrm{RuCl}\left(\mathrm{CH}=\mathrm{CHC}_{4} \mathrm{H}_{9}\right)(\mathrm{CO})$

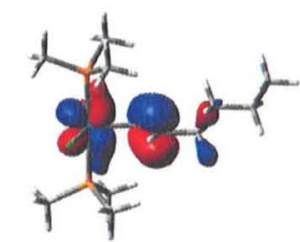

hexenyl

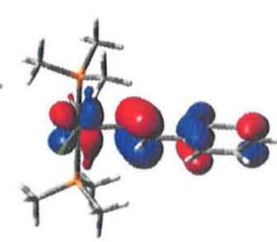

styryl

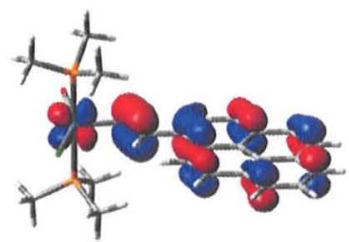

pyrenyl

$\begin{array}{ll}\% \text { metal } & 46 \\ \% \text { ligand } & 47 \\ \Delta v(\mathrm{CO})\left[\mathrm{cm}^{-1}\right] & 77\end{array}$

29

66

65
14

84

48

Fig. 7. Comparison of the experimental oxidation-induced shift of the $v(\mathrm{CO})$ band $\Delta v(\mathrm{CO})$ and of the computationally derived metal and vinyl ligand contribution to the HOMO along with graphical representation of the HOMOs. 


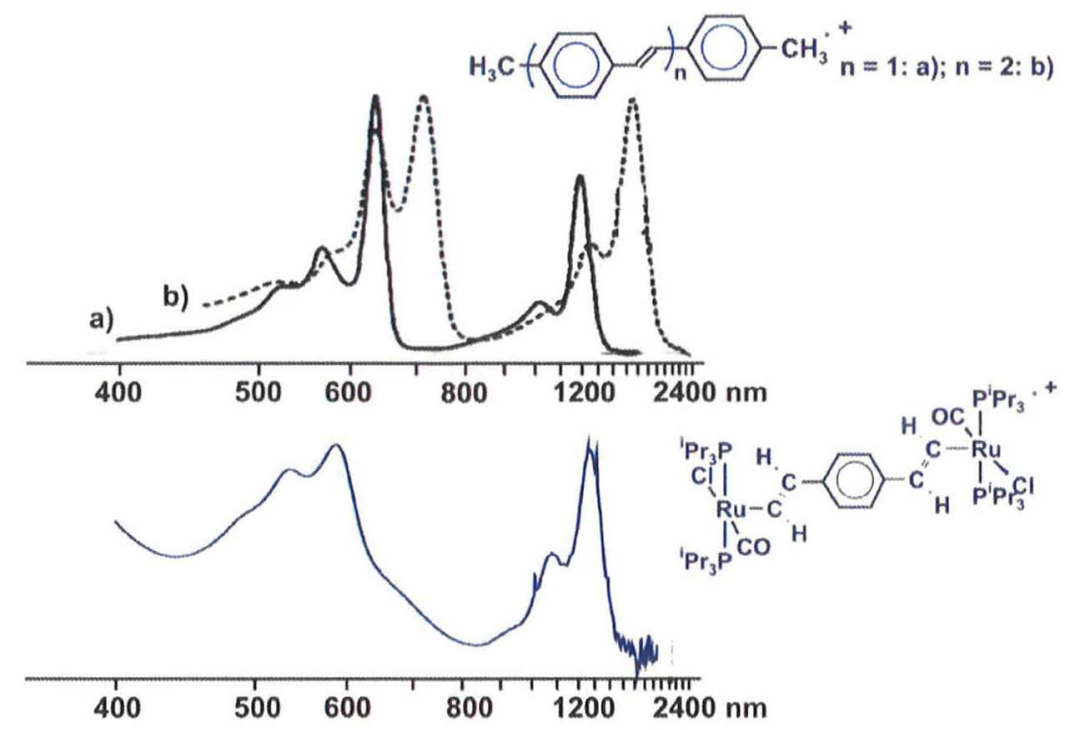

Fig. 8. Comparison of the Vis/NIR spectra of electrogenerated $\left[\left\{\mathrm{RuCl}(\mathrm{CO})\left(\mathrm{P}^{i} \mathrm{Pr}_{3}\right)_{2}\right\}_{2}\left(\mu-\mathrm{CH}=\mathrm{CH}-\mathrm{C}_{6} \mathrm{H}_{4} \mathrm{CH}=\mathrm{CH}-1,4\right)\right]^{+}$and of those of $4,4^{\prime}$ dimethylstyrene and di(4methylstyryl)benzene (adapted from Ref. [71] with permission).

$\left(\mathrm{P}^{i} \mathrm{Pr}_{3}\right)_{2}$ suggest that the simplifications introduced by substitution of the $\mathrm{P}^{i} \mathrm{Pr}_{3}$ ligands by $\mathrm{PMe}_{3}$ do not compromise the general con clusions drawn from the $\mathrm{PMe}_{3}$ models $[60,64]$.

The dominant organic character of arylvinyl substituted ruthe nium complexes also explains, why the electronic spectrum of the radical cation of the divinyl phenylene bridged diruthenium complex $\left\{\mathrm{RuCl}(\mathrm{CO})\left(\mathrm{P}^{i} \mathrm{Pr}_{3}\right)_{2}\right\}_{2}\left(\mu \mathrm{CH}=\mathrm{CH} \mathrm{C}_{6} \mathrm{H}_{4} \mathrm{CH}=\mathrm{CH} 1,4\right)$ closely resembles those of styryl type radical cations and, more specifi cally, that of oxidized distyrylbenzene $[71,72]$. The overall resem blance, as it is documented in Fig. 8, even pertains to the vibrational splitting constants which are virtually identical for both types of systems. From such comparison we can infer that the "RuCl$(\mathrm{CH}=\mathrm{CH})(\mathrm{CO})\left(\mathrm{P}^{i} \mathrm{Pr}_{3}\right)_{2}$ substituent" acts as nearly an as strong electron donor as the $\mathrm{NMe}_{2}$ group while it simultaneously increases the conjugation length of the parent organic chromo phore in basically the same manner as a coplanar phenyl ring. $\mathrm{Vi}$ nyl ruthenium complexes are thus truly delocalized electroactive metal organic $\pi$ systems.

\section{Intramolecular electron transfer in vinyl-bridged diruthenium complexes}

Forays into mononuclear vinyl ruthenium complexes have shown how electrochemistry and molecular spectroscopy in concert provide detailed information about the respective contributions of the metal atom and the ligand to the relevant "redox orbital". We will now go one step further and address complexes with two vinyl ruthenium moieties or one vinyl ruthe nium moiety and another redox active subunit. Here we will pose questions about charge and spin delocalization over the individ ual vinyl ruthenium subunits and the bridging ligand and the rate of intramolecular ET by making use of the various spectroscopic labels offered by the $\mathrm{RuCl}(\mathrm{CO})\left(\mathrm{PR}_{3}\right)_{2}(\mathrm{~L})(\mathrm{CH}=\mathrm{CH}$ ) entities in very much the same manner as it was outlined in Section 2 of this ac count. In doing so, we will provide examples that we consider as being instructive to the reacler. These examples will include linear systems, [2.2]paracyclophane derived systems exhibiting "3D type" delocalization and vinyl complexes having two different re dox active subunits where only one of them is of vinyl ruthenium parentage.

\subsection{Linear divinyl bridged diruthenium complexes}

The first example of this class of compounds pertains to iso meric 1,3 and 1,4 divinylphenylene bridged diruthenium com plexes $\left\{\mathrm{RuCl}(\mathrm{CO})\left(\mathrm{PR}_{3}\right)_{2}(\mathrm{~L})\right\}_{2}\left(\mu \mathrm{CH}=\mathrm{CH} \mathrm{C}{ }_{6} \mathrm{H}_{4} \mathrm{CH}=\mathrm{CH}\right), 3$ and 4 , with $\mathrm{R}=\mathrm{Ph}, \mathrm{L}=4 \times \mathrm{C}_{5} \mathrm{H}_{4} \mathrm{~N}(\mathrm{X}=\mathrm{EtCOO}, \mathrm{OMe}, \mathrm{Me})$ or $\mathrm{R}={ }^{i} \mathrm{Pr}$, $\mathrm{L}=$ none as they are depicted in Chart $4[73,74]$. Liu and coworkers have reported similar studies on a series of divinylphenylene bridged dinuclear complexes $\left[\left\{\mathrm{RuCl}(\mathrm{CO})\left(\mathrm{PMe}_{3}\right)_{3}\right\}_{2}\left(\mu \mathrm{CH}=\mathrm{CH} \mathrm{ph}^{\mathrm{R}}\right.\right.$ $\mathrm{CH}=\mathrm{CH})]\left(\mathrm{ph}^{\mathrm{R}}=\right.$ substituted phenylene unit), but only para isomers were investigated [61]. Every complex of Chart 4 is oxidized in two consecutive one electron waves. The splitting of half wave potentials, $\Delta E_{1 / 2}$, is very similar or even identical for the para and meta isomers. This is somewhat counterintuitive when taking the $\Delta E_{1 / 2}$ as a measure of electron delocalization in the corre sponding singly oxidized MV system. Based on simple consider ations of electronic interactions in para and meta disubstituted benzenes, much more substantial differences of $\Delta E_{1 / 2}$ would have been expected. Such behaviour was e.g. observed for 1,4 and 1,3 diethynylphenylene bridged diruthenium complexes trans $\left\{\mathrm{Cl}(\mathrm{dppm})_{2} \mathrm{Ru}\right\}_{2}\left(\mu \mathrm{C} \equiv \mathrm{C}_{6} \mathrm{H}_{4} \mathrm{C} \equiv \mathrm{C}\right)$, where $\Delta E_{1 / 2}$ amounts to $300 \mathrm{mV}$ for the para and to $190 \mathrm{mV}$ for the meta isomers [75] de spite a similar (though less strongly pronounced) non innocent character of the bis(ethynyl)phenylene bridging ligand [76 79]. EPR spectra of the $\mathrm{PPh}_{3}$ derived radical cation complexes $\mathbf{4 a}-\mathbf{c}^{+}$ give only broadened isotropic signals with no resolved hyperfine splittings and thus provide no information about spin delocaliza tion. For the $\mathrm{P}^{i} \mathrm{Pr}_{3}$ derived systems para $3^{.+}$and meta $3^{\cdot+}$, however, hyperfine splittings to four equivalent ${ }^{31} \mathrm{P}$ and two equivalent ${ }^{99}$ ${ }^{101} \mathrm{Ru}$ nuclei were well resolved. This indicates a symmetrical spin distribution over both vinyl ruthenium subunits for the meta and the para isomer. The faster IR timescale of $10^{12} \mathrm{~s}$, however, reveals a difference: the radical cations of the $\mathrm{PPh}_{3}$ derived complexes para-4a-c display only one single CO band indicating that the two $\mathrm{RuCl}(\mathrm{CO})\left(\mathrm{PPh}_{3}\right)_{2}\left(4 \times \mathrm{C}_{5} \mathrm{H}_{4} \mathrm{~N}\right)$ moieties are electronically equivalent. The five coordinated $\mathrm{P}^{i} \mathrm{Pr}_{3}$ radical cation para- $3^{+}$is a less clear cut case in that two sets of overlapping $\mathrm{Ru}(\mathrm{CO})$ bands are observed, one with a single $\mathrm{CO}$ band and one consisting of two closely spaced $\mathrm{Ru}(\mathrm{CO})$ bands. The reason of such behaviour is still not entirely understood. A possible explanation is the coexistence of two isomers differing in the degree of electron 


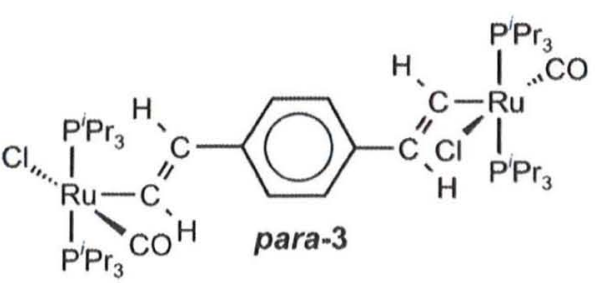

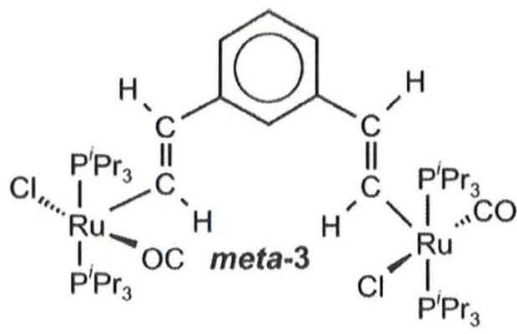

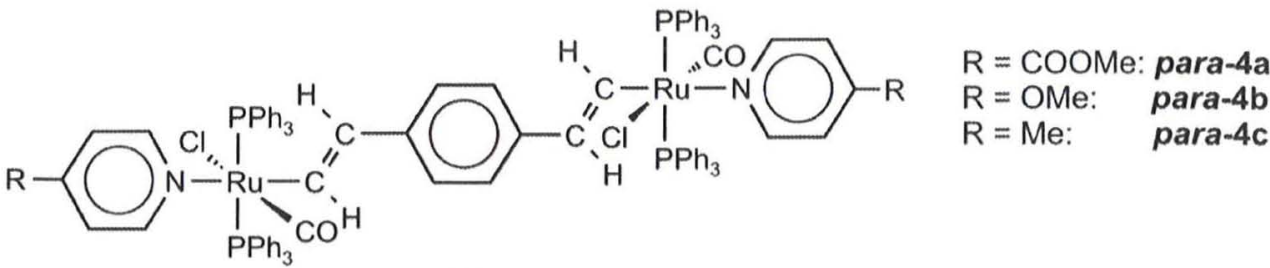<smiles></smiles>

Chart 4. Divinylphenylene-bridged diruthenium complexes studied by us.

delocalization, possibly rotamers whose charge delocalization de pends on the mutual orientations of the $\mathrm{Ru}(\mathrm{CO}) \mathrm{Cl}$ vectors [74].

All meta isomers, however, display a two band pattern with the CO band at the lower energy blue shifted with respect to the neu tral complex and the higher energy band red shifted with respect to the doubly oxidized dication. This is the typical signature of MV systems of Class II with partially localized valencies and non symmetrical charge distributions over the two vinyl ruthenium subunits. Interestingly, the relative $\mathrm{CO}$ band shift as defined in Eq. (5) and illustrated in Fig. 9 yields a so called charge delocaliza tion parameter $\Delta \rho$ which provides a quantitative measure of ground state charge delocalization $[27,28]$. By the definition of Eq. (5), $\Delta \rho$ may vary between the limits of 0 and 0.5 . The lower limit of $\Delta \rho=0$ characterizes MV systems of Class I with fully local ized valencies. Here the lower and higher energy CO bands of the MV state are at the same position as in the neutral or in the diox

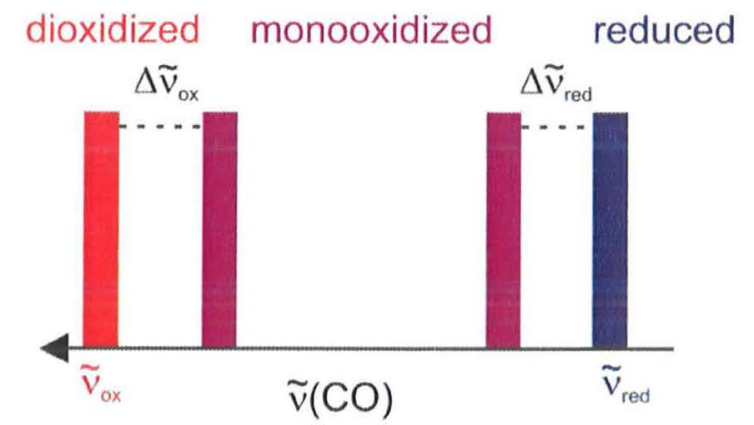

Fig. 9. Illustration of the band shifts utilized in determining the charge delocalization parameter. idized systems where both electroactive subunits are isovalent. In the other extreme, $\Delta \rho=0.5$ denotes the limit of full charge delocal ization where a single set of $\mathrm{CO}$ bands occurs at positions midway between those for the neutral and the dioxidized isovalent states. The relative $\mathrm{CO}$ band shifts for the three meta linked $\{\mathrm{RuCl}$ $\left.(\mathrm{CO})\left(\mathrm{PPh}_{3}\right)_{2}\left(4 \times \mathrm{C}_{5} \mathrm{H}_{4} \mathrm{~N}\right)\right\}_{2}\left(\mu \mathrm{CH}=\mathrm{CH} \mathrm{C}_{6} \mathrm{H}_{4} \quad \mathrm{CH}=\mathrm{CH} 1,3\right) \quad$ com plexes yield $\Delta \rho$ values in the range of $2532 \%$, indicating that they are significantly coupled MV systems of Class II. For the radical cat ions of the meta isomers, intramolecular ET thus seems to occur at a time scale in between the EPR and IR time domains $\left(10^{8}<k_{\mathrm{ET}}<10^{12} \mathrm{~S}{ }^{1}\right)$, while the radical cations of the para isomers are intrinsically delocalized MV radical cations of Class III.

$\Delta \rho \quad \Delta \tilde{v}_{\text {ox }} \quad \Delta \tilde{v}_{\text {red }} / 2\left(\tilde{v}_{\text {ox }} \quad \tilde{v}_{\text {red }}\right)$

Insertion of a further styryl unit into the bridge generates the distyrylethene bridged diruthenium complexes $\mathbf{5}$ and $\mathbf{6}$ of Chart 5. These may exist as cis or trans isomers, where the stereochemical descriminator pertains to the mutual disposition of the two styryl ruthenium subunits around the central $\mathrm{C}=\mathrm{C}$ double bond. We were successful in preparing and structurally characterizing both iso mers. As one might have expected, the central $\mathrm{Ru} \mathrm{CH}=\mathrm{CH} \mathrm{C}_{6} \mathrm{H}_{4}$ $\mathrm{CH}=\mathrm{CH} \mathrm{C} \mathrm{C}_{6} \mathrm{H}_{4} \mathrm{CH}=\mathrm{CH}$ Ru unit of the trans isomer is fully planar, while in the cis isomer the phenyl planes are inclined by $38^{\circ}$. The trans isomer is oxidized in two consecutive one electron oxida tions with a $\Delta E_{1 / 2}$ of just $35 \mathrm{mV}\left(K_{\text {comp }}=4\right)$ as shown by digital simulations of the experimental cyclic and square wave voltam mograms. Such small redox splitting suggests an only modest elec tronic coupling between the styryl ruthenium subunits in the MV state. IR spectroscopy on the radical cation shows two separate CO bands, and both of them are appreciably shifted from their posi tions in the neutral and the dioxidized forms.

Electrocatalytic cis to trans isomerization at the radical cation stage $\mathbf{6}^{+}$renders similar studies on the cis isomer impossible. We 


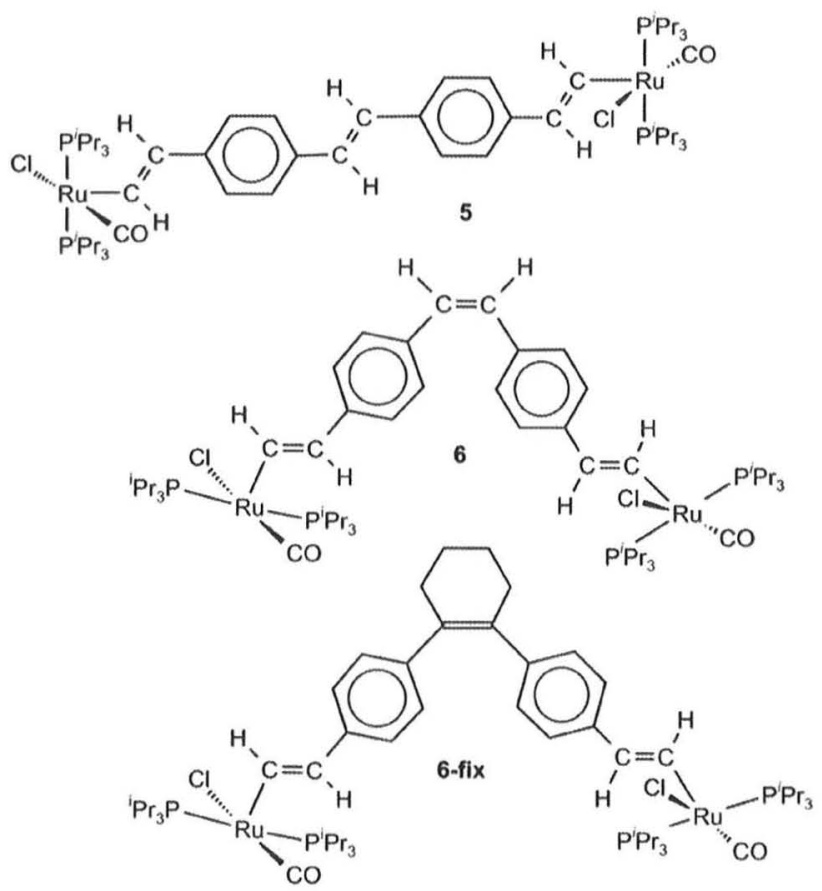

Chart 5. Distyrylbenzene-bridged diruthenium complexes studied by us.

therefore had to resort to a "cis fixated" analog $\mathbf{6 - f i x}$ where the central $\mathrm{C}=\mathrm{C}$ double bond is incorporated into a cyclohexene ring (see Chart 5). This compound oxidizes in two consecutive one elec tron oxidation steps that are spaced by $63 \mathrm{mV}\left(K_{\text {comp }}=12\right)$ and thus by a larger amount than in the trans isomer. On stepwise oxi dation we also observe a two band pattern for the radical cation with, however, significantly smaller relative CO band shifts than for the trans isomer. Data analysis yields $\Delta \rho$ values of $23 \%$ and $8 \%$ for the trans and the cis fixated isomers $\mathbf{5}^{+}$and $\mathbf{6}$-fix ${ }^{+}$. This is a case where $\Delta E_{1 / 2}$ and the "true" electronic coupling follow opposite trends. Coulomb contributions $\Delta G_{\mathrm{e}}$ and the greater spatial proximity between the redox sites obviously override the reso nance contribution $\Delta G_{\text {res }}$ to $\Delta G$ and $K_{\text {comp. }}$.

\subsection{Vinyl diruthenium complexes derived from cyclophanes}

[n.n]Paracyclophanes are ideal testbeds for studying delocaliza tion between stacked arene decks [80]. The groups of Neugebauer $[81,82]$ and, more recently, Grampp and Lambert [83] have utilized EPR spectroscopy to probe for spin delocalization in radical cations derived from electron rich methoxy or bis(triarylamine) substi tuted [n.n]paracyclophanes. The decrease of electronic coupling with increasing extensions of the individual $\pi$ decks and with increasing lengths of the alkyl straps were ascribed to the dilution of spin density on each of the conjoined, parallel displaced benzene rings and the decreased likeliness with which the system adopts conformations with small stacking distances.

We felt that the presence of the $\mathrm{Ru}(\mathrm{CO})$ units and the incremen tal CO band shifts upon stepwise oxidation would allow us to probe for intrinsic charge delocalization in such systems on the fas ter IR timescale. We thus prepared and investigated the pseudo para(distyrylruthenium) [2.2]paracyclophane complex $\mathbf{8}$ of Chart 6 and the mononuclear and "half open" derivatives 7 and $\mathbf{9}$. X ray structure analysis of $\mathbf{8}$ shows the expected features of this class of compounds such as a boatlike distortion of the arene decks with

the linked bridgehead carbon atoms as the bow and stern, a stack ing distance of $3.065 \AA$ between the best planes of the remaining four carbon atoms of each deck and near coplanarity of the ruthe nium vinyl unit and the plane of the four non bridgehead carbon atoms of each deck. Complex $\mathbf{8}$ is oxidized in two consecutive one electron steps with $\Delta E_{1 / 2}$ of $215 \mathrm{mV}$. In its IR spectrum, radical cation $\mathbf{8}^{+}$shows two well separated $v(\mathrm{CO})$ bands. Again the low energy band is blue shifted with respect to the single $\mathrm{CO}$ band of the neutral. Further oxidation to the dication $\mathbf{8}^{2+}$ restores the one $\mathrm{CO}$ band pattern and reveals that the higher energy CO band of the radical cation is appreciably red shifted with respect to the carbonyl absorption of the dication. As discussed before, the relative $\mathrm{CO}$ band shifts of the radical cation provide a quantitative measure for ground state delocalization. The charge delocalization parameter $\Delta \rho$ thus obtained is 0.08 . This essentially means that one of the $\mathrm{Ru}(\mathrm{CO})$ subunits bears less than $10 \%$ of the total positive charge on both $\mathrm{Ru}(\mathrm{CO})$ entities while the remaining $>90 \%$ reside on the other one.

There is a general consensus that through space (i.e. $\pi$ stacking) and through bond pathways (i.e. electron delocalization over the alkylene straps) are both relevant for electron delocalization in [n.n]paracyclophanes $[30,83]$. Several examples in the literature report on nonzero electronic couplings over simple alkyl connec tors [84 88]. It is nevertheless hard to extract any quantitative information as to the relative contributions of the two complemen tary pathways from the literature data. In order to assess the rela tive contributions of the $\pi$ stacking and $\sigma$ bond pathways to the total delocalization we have prepared and investigated complex 9 of Chart 6. Complex 9 can be regarded as a half open orthocyclo phane. The placement of an ethylene linker para to the vinyl ruthe nium units and of a shorter methylene linker meta to them was intended to render both $\sigma$ bond pathways as similar to complex 8 as possible and to prevent conformations with parallel displaced arene decks. Complex $\mathbf{9}$ also undergoes two consecutive reversible one electron oxidations which are separated by $105 \mathrm{mV}$. Stepwise oxidation inside a thin layer electrolysis cell first generates the rad ical cation and then the dication. In this case the low energy CO stretch of $\mathbf{9}^{+}$appears at nearly the same energy as in $\mathbf{9}$ while the

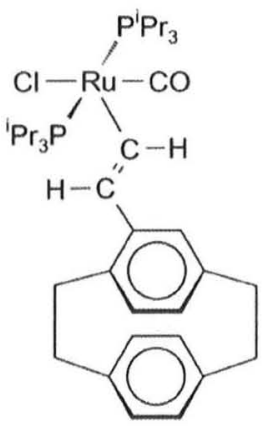

7

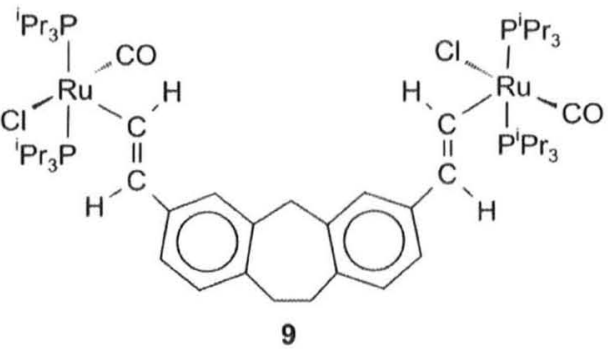

Chart 6. Cyclophane-derived vinyl ruthenium complexes studied by us. 
band at higher energy is very close to the position of the $\mathrm{CO}$ band of $\mathbf{9}^{2+}$. From the IR criterion we can estimate the charge delocalization parameter of $\mathbf{9}^{+}$as about 0.01 , which is substantially smaller than that in $\mathbf{8}^{+}$. Ground state delocalization in $\mathbf{8}^{+}$is a result of the com bined effects of the through space and through bond pathways. In the half open cyclophane $\mathbf{9}^{+}$a parallel arrangement of the arene decks is conformationally unattainable. This particular constella tion renders the through bond pathway the main contributor to the total electron delocalization in $\mathbf{9}^{+}$. From the comparison of the $\Delta \rho$ parameters of $\mathbf{8}^{+}$and $\mathbf{9}^{+}$we therefore conclude that $\pi$ stacking constitutes the major pathway for overall electron delo calization in radical cations of [2.2]paracyclophanes while the through bond pathway contributes considerably less [89].

\subsection{Mixed systems with only one vinyl ruthenium unit}

The systems discussed in the previous sections were intended as illustrative examples of how vinyl ruthenium moieties can be employed to measure electron or spin delocalization in mixed va lent systems incorporating two identical such units. In this final section we provide two examples of how they can be employed for measuring delocalization in MV systems containing two differ ent redox active moieties where only one of them is of vinyl ruthe nium parentage. The first example is the ferrocenyl vinyl complex $\mathrm{Fc} \mathrm{CH}=\mathrm{CH} \mathrm{RuCl}(\mathrm{CO})\left(\mathrm{P}^{i} \mathrm{Pr}_{3}\right)_{2}(\mathbf{1 0}$, Chart 7) which is easily accessi ble from the hydroruthenation of ethynylferrocene. Complex $\mathbf{1 0}$ is oxidized in two one electron steps with a large $\Delta E_{1 / 2}$ of $715 \mathrm{mV}$ which, however, this time is also due to the difference in intrinsic redox potentials of the two different redox active sub units. Structural comparison between the neutral and the chemi cally oxidized radical cation shows the familiar changes associated with the ferrocene to ferrocenium transformation such as a lengthening of all $\mathrm{Fe} \mathrm{C}$ bonds and a tilting of the cyclopenta dienyl rings from a coplanar arrangement. There are, however, structural indications for the loss of charge from also the vinyl ruthenium part of this complex. Thus, the Ru vinyl bond contracts by $4 \mathrm{pm}$ while the $\mathrm{Ru} \mathrm{C}(\mathrm{CO})$ bond elongates by $3 \mathrm{pm}[90]$.

Moessbauer and EPR spectra measured on powdered samples establish an only partial ferrocenium character of the radical cation and sizable charge and spin delocalization onto the vinyl ruthe nium unit. Oxidation of $\mathbf{1 0}$ to $\mathbf{1 0}^{+}$diminishes the Moessbauer quadrupole splitting from 2.33 to $0.92 \mathrm{~mm} \mathrm{~s}^{1}$. While such behav iour is indicative of the loss of electron density from the ferrocenyl site, the observed quadrupole splitting of $10^{+}$is appreciably larger as that for simple ferrocenium cations where it is usually lower than $0.15 \mathrm{~mm} \mathrm{~s}^{1}$ and often below the resolution limit. The EPR signal of $\mathbf{1 0}^{+}$is already observed under liquid nitrogen cooling and displays the typical axial pattern of ferrocenium cations, but with an unusually small $g$ anisotropy of less than 1 . The parent fer rocenium ion and its simple ring substituted derivatives typically show $\Delta g>2$ [91]. Both these anomalies are characteristic of ferro cenium type radical cations, where the ferrocenium moiety is embedded into an extended, $\pi$ conjugated system or of partially delocalized biferrocenium radical cations. Hendrickson and others

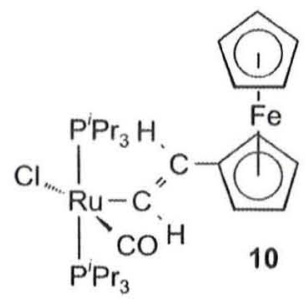

Chart 7. The ferrocenyl vinyl ruthenium complex studied by us.
[92] have established that $\Delta g$ and the quadrupole splitting scale linearly with the fraction $\delta+$ of a unipositive charge on the ferro cene part of such structures. Taking their relations one arrives at a $\delta$ value of 0.8 for solid samples at liquid nitrogen temperature.

We can again nicely employ IR spectroscopy for monitoring the charge distribution in fluid solution. Here, the $\mathrm{Ru}(\mathrm{CO})$ band shifts

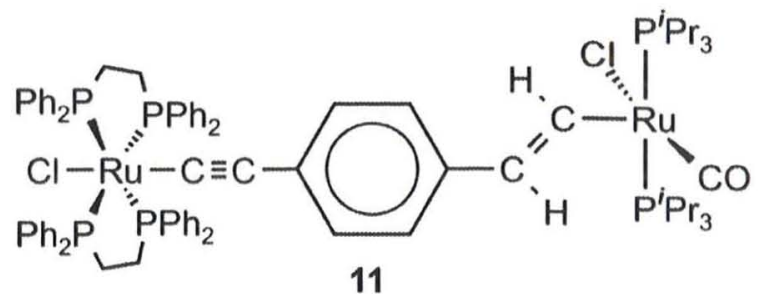
11

$$
\begin{array}{ccc}
\mathrm{n}= & 0 & 1 \\
\widetilde{v}(\mathrm{C} \equiv \mathrm{C})=2065 & 2061,1967 \\
\widetilde{v}(\mathrm{C} \equiv \mathrm{O})=1910 & 1929 \\
\widetilde{v}_{\max }= & 7460 \mathrm{~cm}^{-1} \\
\mathrm{E}_{1 / 2}{ }^{1 /+}=-0.22 \mathrm{~V}, \mathrm{E}_{1 / 2}^{+/ 2+}=+0.14 \mathrm{~V}
\end{array}
$$

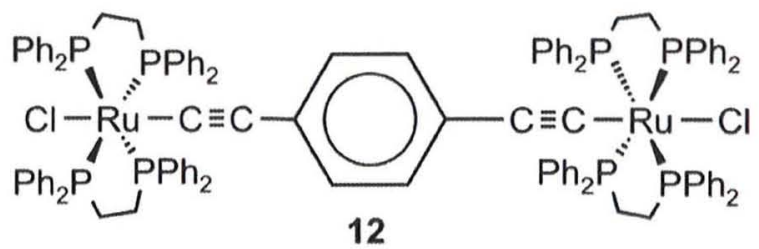

$$
\begin{array}{cccc}
\mathrm{n}= & 0 & 1 & 2 \\
\widetilde{\nabla}(\mathrm{C} \equiv \mathrm{C})=2071 & 2068,1966 & 1918 \\
\nabla_{\max }= & 6553 \mathrm{~cm}^{-1} \\
\mathrm{E}_{1 / 2}{ }^{0 /+}=-0.33 \mathrm{~V}, \mathrm{E}_{1 / 2}^{+/ 2+}=+0.01 \mathrm{~V}
\end{array}
$$

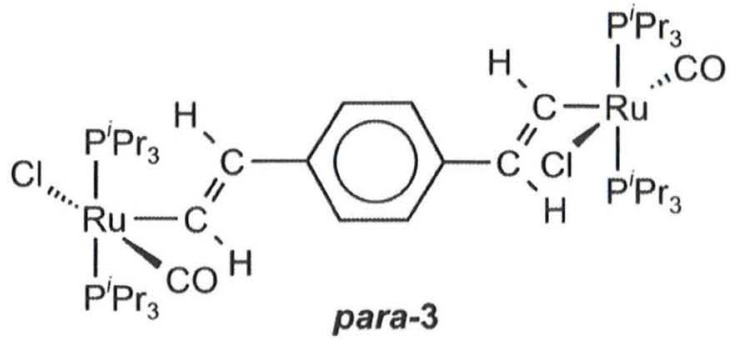

para-3

$$
\begin{array}{cccc}
\mathrm{n}= & 0 & 1 & 2 \\
\widetilde{\mathrm{v}}(\mathrm{C} \equiv \mathrm{O})=1910 & 1932 & 1991 \\
\nabla_{\max }= \\
\mathrm{E}_{1 / 2}^{0 /+}=-0.075 \mathrm{~V}, \mathrm{E}_{1 / 2}^{+/ 2+}=+0.175 \mathrm{~V}
\end{array}
$$

Chart 8. Spectroscopic data of the diethynylphenylene-bridged complex 12, the divinylphenylene-bridged diruthenium complex para-3 and the mixed alkynyl/ vinyl phenylene-bridged complex $\mathbf{1 1}$ in their various oxidation states. 


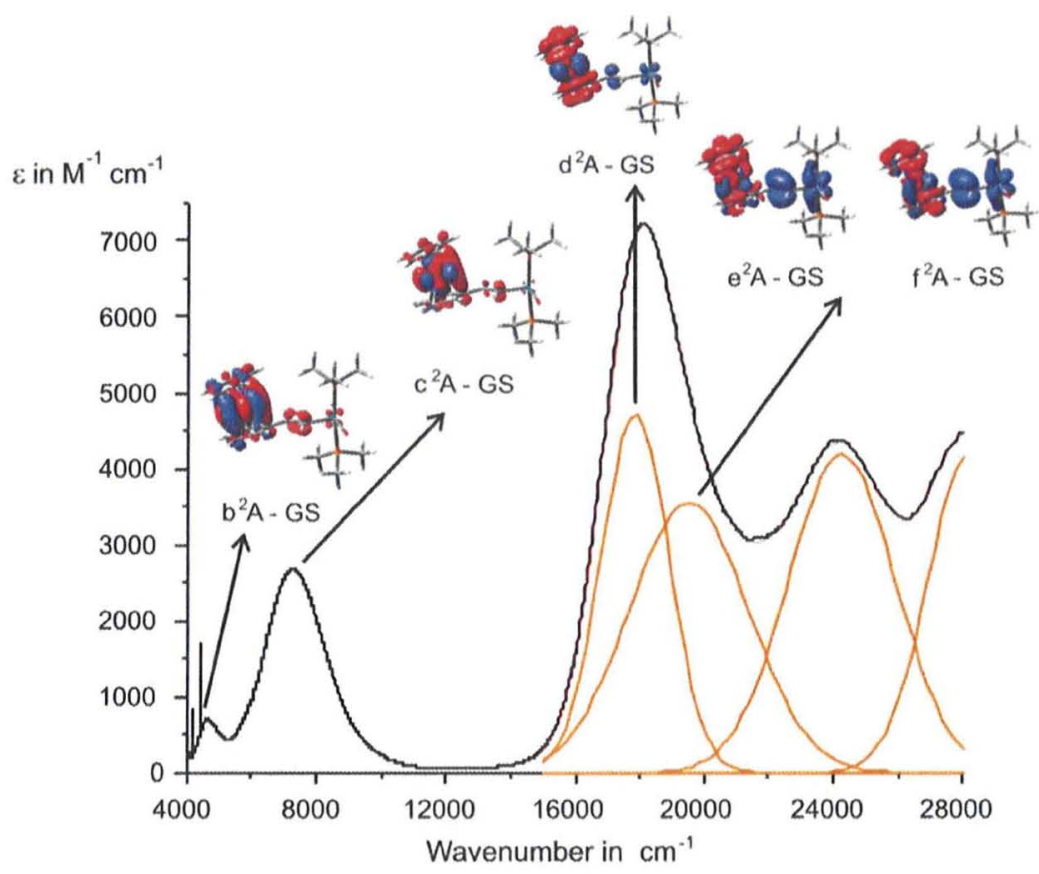

Fig. 10. Vis/NIR spectrum of radical cation $\mathbf{1 0}^{+}$along with a deconvolution of the Vis bands and the charge density changes calculated by TD DFT. The plots show the charge shifts for each relevant excitation. Blue colour denotes diminishing electron densities and red colour denotes increasing electron densities.

by $24 \mathrm{~cm}{ }^{1}$, which is $40 \%$ of the value in the related styryl complex $\mathrm{RuCl}(\mathrm{CH}=\mathrm{CHPh})(\mathrm{CO})\left(\mathrm{P}^{i} \mathrm{Pr}_{3}\right)_{2}$. By virtue of the $v(\mathrm{CH})$ of the cyclopen tadienyl ligands, complex 10 provides yet another charge sensitive IR label which is now attached to the ferrocene part of the struc ture. Here, $v(\mathrm{CH})$ experiences a blue shift of $14 \mathrm{~cm}{ }^{1}$, which is $60 \%$ of the value of the parent $\mathrm{FcH} / \mathrm{FcH}^{+}$redox system [93]. Inter estingly, solid samples show somewhat different values. Here the CO band shift reduces to $10 \mathrm{~cm}^{1}$ while $\Delta v(\mathrm{CH})$ increases to $24 \mathrm{~cm}^{1}$. The amount of charge on the $\mathrm{Fc}^{\delta+}$ and the Ru $\left.\mathrm{CH}=\mathrm{CH}^{(1} \quad \delta\right)^{+}$sites thus seems to depend on the environment. A close inspection of the crystallographic structure of $\mathbf{1 0} \mathbf{P F}_{6}$ offers a possible key to the reasons underlying this behaviour. The $\mathrm{PF}_{6}$ anions show no positional disorder and are associated to the cyclo pentadienyl rings of the ferrocenyl substituents by a total of three $\mathrm{CH}$ F hydrogen bonds that range from 2.37 to $2.52 \AA$. This ties the $\mathrm{PF}_{6}$ counterions to the $\mathrm{Fc}^{j+}$ part of the structure and away from the $\mathrm{Ru} \mathrm{CH}=\mathrm{CH}$ unit. Association through Coulombic forces may thus account for the higher charge concentration on the $\mathrm{Fc}^{\mathrm{c}+}$ site in the solid state and in polar environments as opposed to less polar solvents. Although similar counterion effects on charge delo calization are well documented for biferrocenium radical cations [94 101], the above hypothesis still calls for verification through radical cation salts of more or less coordinating anions than $\mathrm{PF}_{6}$. Work along these lines is presently being pursued in our laboratories.

At this point we recall our statement that the identification of an IVCT band in MV systems as such may be anything but trivial. The mixed $[\mathrm{Fc} \mathrm{CH}=\mathrm{CH}\{\mathrm{Ru}\}]^{+}$cation $\mathbf{1 0}^{+}$offers a nice example of such notion. The electronic spectrum of $\mathbf{1 0}^{+}$features several bands in the visible and in the NIR that grow in during the first oxidation [90]. Time dependent density functional (TD DFT) calculations have been performed in an attempt to identify the underlying elec tronic transitions. The results of that study are displayed in Fig. 10 along with the experimental absorption spectrum. The redistribu tion of electron density upon every relevant electronic transition is indicated by colour coding where the blue colour marks regions from which electron density is lost and the red one those which gain electron density. The two low energy NIR bands which are the logical candidates of an IVCT type transition are calculated to involve the $\mathrm{Fe}$ based $\delta$ orbitals of the $\mathrm{Fc}^{\delta+}$ subunit with very minor charge transfer to the $\left.\mathrm{CH}=\mathrm{CH} \mathrm{Ru}^{(1} \delta\right)^{+}$site. This is because the receptor orbital weakly interacts with the $\mathrm{CH}=\mathrm{CH} \mathrm{Ru}$ "substitu ent" while the donor orbital does not. The next, rather intense band in the experimental spectrum is due to an overlap of two underly ing transitions as is shown by TD DFT and by the comparison of experimental spectra in solvents of different polarity. The lower energy component is calculated to involve charge transfer within the $\mathrm{Fc}^{\delta+}$ part of the molecule from the iron atom to the $\pi^{*}$ orbitals of the Cp rings. The higher energy component is calculated to con sist of two nearly degenerate transitions involving charge transfer from the vinyl ruthenium to mostly $C p$ based $\pi^{*}$ orbitals of the fer rocene unit. This band is perhaps closest to an IVCT transition.

The final example involves mixed ethynyl/vinyl phenylene bridged diruthenium systems. Within the field of organometallic mixed valent systems, 1,4 diethynylphenylene bridged dinuclear complexes have gained particularly popularity. This is mainly due to the good propensity of the 1,4 diethynylpheylene linker to electronically couple the bridged metal sites. It has turned out, however, that while such kind of reasoning is fully appropriate for most metal complexes, this is not so in the diruthenium case. The reason is the same as for the divinylphenylene bridged coun terparts: The HOMO of the reduced forms and the SOMO of the mixed valent radical cations of diruthenium complexes are not metal based but are mainly centred on the bridging ligand [76 79]. Few systems with two different metal endgroups have also ap peared in the literature [ 102 105]. In these cases, the primary oxi dation is more or less localized on just one metal ethynyl site due to a pronounced redox asymmetry resulting from a large differ ence in oxidation potentials between the individual metal ethynyl sites. The iron ruthenium complexes trans $\mathrm{X}(\mathrm{dppe})_{2} \mathrm{Ru} \mathrm{C}=\mathrm{C}$ $\mathrm{C}_{6} \mathrm{H}_{4} \mathrm{C} \equiv \mathrm{C}$ Fe(dppe) $\mathrm{Cp}^{*}$ (dppe $=1,2$ bis(diphenylphosphanyl)eth ane, $C p^{*}=\eta^{5} \mathrm{C}_{5} \mathrm{Me}_{5}, \mathrm{X}=\mathrm{Cl}, \mathrm{C}=\mathrm{CPh}$ ) are an exception in that their radical cations are appreciably coupled mixed valent systems of Class II [106]. The intrinsic redox potentials of the 1,4 diethynyl 
phenylene bridged diruthenium complexes trans $\left\{X(d p p e){ }_{2} R u\right\}_{2}(\mu$ $\mathrm{C}=\mathrm{C} \mathrm{C}_{6} \mathrm{H}_{4} \mathrm{C}=\mathrm{C}$ ) [107] and the 1,4 divinylphenylene bridged diruthenium complex $\left\{\left(\mathrm{P}^{i} \mathrm{Pr}_{3}\right)_{2}(\mathrm{CO}) \mathrm{ClRu}\right\}_{2}\left(\mu \mathrm{CH}=\mathrm{CH} \mathrm{C}_{6} \mathrm{H}_{4} \mathrm{CH}=\mathrm{CH}\right)$ [74] are rather close. This prompted us to investigate the mixed 1 ethynyl 4 vinylphenylene bridged complex 11 which blends both these motifs into one single system (see Chart 8) [108].

The mere comparison of redox potentials already shows a pro found mutual influence of the two sites. Replacing the powerful $\mathrm{Cl}$ (dppe $)_{2} \mathrm{Ru} \mathrm{C}=\mathrm{C}$ donor by the less potent $\left(\mathrm{P}^{i} \mathrm{Pr}_{3}\right)_{2}(\mathrm{CO}) \mathrm{ClRu}$ $\mathrm{CH}=\mathrm{CH}$ one shifts the first oxidation potential anodically by $110 \mathrm{mV}$ with respect to the bis(ethynyl) phenylene bridged com plex $\left[\left\{\mathrm{Cl}(\mathrm{dppe})_{2} \mathrm{Ru}\right\}_{2}\left(\mu \mathrm{C}=\mathrm{C} \mathrm{C}_{6} \mathrm{H}_{4} \mathrm{C}=\mathrm{C} 1,4\right)\right] \mathbf{1 2}$ [107] while the second oxidation occurs at less positive potential than that in the divinylphenylene bridged system para-3. From the comparison of the redox potentials one might guess that the first oxidation is more biased on the ethynylruthenium site. Again we resorted to the reporter qualities of the vinyl ruthenium moiety in order to measure electron delocalization in the mixed valent state.

The $\mathrm{C}=\mathrm{C}$ and $\mathrm{CO}$ stretching frequencies for the neutral, the rad ical cations and the dioxidized dications of these species are col lected in Chart 8. It turns out that the main $C=C$ stretch of the radical cation of the "mixed" complex $\mathbf{1 1}$ at $1967 \mathrm{~cm}{ }^{1}$ is at virtu ally the same position as in the monooxidized bis(ethynyl)pheny lene bridged system $\mathbf{1 2}^{+}$. Moreover, the absolute shift is half of that found in the trimethylsilyl protected or unprotected precursors trans $\mathrm{XRu}(\mathrm{dppe})_{2}\left(\mathrm{C} \equiv \mathrm{C} \mathrm{C}_{6} \mathrm{H}_{4} \mathrm{C} \equiv \mathrm{CR}\left(\mathrm{R}=\mathrm{H}, \mathrm{SiMe}_{3}\right)\right.$. In addition, the position of the $\mathrm{CO}$ band matches that in the radical cation of the symmetrical divinylphenylene bridged system para-3. From this we conclude that the radical cation $\mathbf{1 1}^{+}$is fully delocalized de spite the unlike $\{\mathrm{Ru}\} \mathrm{C}_{2} \mathrm{H}_{n}$ endgroups.

Moreover, the NIR band of $\mathbf{1 1}^{+}$is positioned midway between those of its symmetrical counterparts para- $3^{++}$and $\mathbf{1 2}^{+}$. The same holds for the EPR signatures. As for the divinylphenylene bridged radical cation para- $3^{+}$, the spectrum is isotropic in fluid or frozen solution and in the solid, but the isotropic $g$ value is in between those of para- $\mathbf{3}^{+}$and $\mathbf{1 2}^{+}$. In summary, the mixed ethynyl/vinyl system is an example of a completely delocalized metal organic MV system with two redox active subunits of different parentage. This is despite the intrinsically different oxidation potentials of its two constituents.

\section{Conclusions}

The present account summarizes our work devoted to utilizing vinyl ruthenium moieties for monitoring charge and spin delocal ization within the vinyl ruthenium moiety itself and in MV systems containing two such units. Our studies on mononuclear vinyl ruthenium complexes have shown that they resemble electron rich organic phenylene vinylenes with respect to their redox properties and do not display metal based oxidations. The vinyl ruthenium functionality is easily integrated into organic $\pi$ systems and endows them with superior thermodynamic stabilities of even the higher oxidized forms (considering that the oxidations are mostly ligand centred) and further modification of their properties by substitution at the organic and the metal part of these struc tures is simple. Together with this stabilizing property, the avail ability of the characteristic and charge sensitive $\mathrm{Ru}(\mathrm{CO})$ absorptions and their EPR activity make vinyl ruthenium com plexes excellent markers for investigating intramolecular electron transfer processes. Absolute IR band shifts are indicative of metal contribution to the "redox orbital" while the number of $\mathrm{CO}$ bands and their relative shifts provide quantitative information on intrin sic ground state delocalization in their mixed valent states.

Our results on the 1,3 divinylphenylene bridged diruthenium complex $\left[\left\{\left(\mathrm{P}^{i} \mathrm{Pr}_{3}\right)_{2}(\mathrm{CO}) \mathrm{ClRu}\right\}_{2}\left(\mu \quad 1,3 \mathrm{CH}=\mathrm{CH} \quad \mathrm{C}_{6} \mathrm{H}_{4} \mathrm{CH}=\mathrm{CH}\right)\right]^{+}$have provided an example of how the availability of different spectro scopic labels that respond to different timescales helps to establish the rate of intramolecular electron transfer. Other examples have shown that the splitting of redox potentials, while providing quan titative information on the thermodynamic stability of a MV com pound with respect to the bordering isovalent ones, does not necessarily scale with the electronic coupling. This is particularly so, when isomers differing with respect to the spatial distance be tween the redox sites and thus with respect to the strength of the electrostatic interactions are compared. We have also documented that low energy absorptions of MV compounds need not necessar ily be IVCT bands and other origins have to be considered. This is important if misinterpretations based on Hush type analyses of such bands of unclear origin are to be avoided. In the light of our results, even the specific appearance of such a band in the MV state is no unequivocal proof for its IVCT character. One final comment pertains to the last set of systems with two different redox sites: even if the intrinsic redox potentials of the different constituents suggests a certain order of redox events, one can never be entirely sure and their MV states may still exhibit substantial charge and spin delocalization. It remains to be explored, how "organic" vinyl ruthenium complexes just are and how they perform as markers in systems of even increased complexity.

\section{Acknowledgements}

R.F. Winter wishes to acknowledge the contributions of those coworkers who were not mentioned as coauthors; their names can be found in the cited literature. He also expresses his gratitude to collaborators and colleagues who have helped with measure ments, by providing samples of special alkynes or with their com ments and helpful discussions. Great many thanks also go out to the various funding agencies who have financially supported the work presented here: Deutsche Forschungsgemeinschaft (DFG, Grants No. Wi1262/7 1 and 7 2), DAAD (joint PROCOPE project with Prof. Stéphane Rigaut, Université de Rennes), Bayerisch Fran zösisches Hochschulzentrum (collaboration with Prof. Michael Knorr, Université de Besançon), and Alexander von Humboldt Stif tung (post doctoral support for Dr. Konrad Kowalski, University of Łódž). S. Záliš also wishes to acknowledge the Grant Agency of the Academy of Sciences of the Czech Republic and the Ministry of Education of the Czech Republic (Grant No. LD11086) for financial support (Grant KAN100400702).

\section{References}

[1] P.J. Low, Dalton Trans. (2005) 2821.

[2] C. Creutz, H. Taube, J. Am. Chem. Soc. 91 (1969) 3988.

[3] J.E. Sutton, H. Taube, Inorg. Chem. 20 (1981) 3125.

[4] D.E. Richardson, H. Taube, Coord. Chem. Rev. 60 (1984) 107

[5] W. Kaim, A. Klein, M. Glöckle, Acc. Chem. Res. 33 (2000) 755.

[6] J.-P. Launay, Chem. Soc. Rev. 30 (2001) 386.

[7] M.B. Robin, P. Day, Adv. Inorg. Chem. Radiochem. 10 (1967) 247.

[8] B. Brunschwig, C. Creutz, N. Sutin, Chem. Soc. Rev. 31 (2002) 168.

[9] C. Lambert, G. Nöll, J. Am. Chem. Soc. 121 (1999) 8434

[9] C. Lambert, G. Nöll, J. Am. Chem. Soc. 121
[10] S.F. Nelsen, Chem. Eur. J. 6 (2000) 581.

[11] S.F. Nelsen, M.N. Weaver, J.P. Telo, J. Am. Chem. Soc. 129 (2007) 7036

[12] K.D. Demadis, E.-S. El-Samanody, G.M. Coia, T.J. Meyer, J. Am. Chem. Soc. 121 (1999) 535

[13] S.E. Bailey, J.I. Zink, S.F. Nelsen, J. Am. Chem. Soc. 125 (2003) 5939.

[14] A.V. Szeghalmi, M. Erdmann, V. Engel, M. Schınitt, S. Amthor, V. Kriegisch, G. Nöll, R. Stahl, C. Lambert, D. Leusser, D. Stalke, M. Zabel, J. Popp, J. Am. Chem. Soc. 126 (2004) 7834

[15] R. Warratz, H. Aboulfadl, T. Bally, T. Tuczek, Chem. Eur. J. 15 (2009) 1604.

[16] J.V. Lockhard, J.I. Zink, Y. Luo, M.N. Weaver, A.E. Konradsson, J.W. Fowble, S.F. Nelsen, J. Am. Chem. Soc. 128 (2006) 16524

[17] B. Badger, B. Brocklehurst, Trans. Faraday Soc. 66 (1970) 2939

[18] B. Badger, B. Brocklehurst, R.D. Russell, Chem. Phys. Lett. 1 (1967) 122.

[19] D. Sun, S.V. Rosokha, J.K. Kochi, J. Am. Chem. Soc. 125 (2004) 1388

[20] J.E. Sutton, P.M. Sutton, H. Taube, Inorg. Chem. 18 (1979) 1017.

[21] C.E.B. Evans, M.L. Naklicki, A.R. Rezvani, C.A. White, V.V. Kondratiev, R.J Crutchley, J. Am. Chem. Soc. 120 (1998) 13096. 
[22] Y.-C. Lin, W.-T. Chen, J. Tai, D. Su, S.-Y. Huang, I. Lin, J.-L. Lin, M.M. Lee, M.F. Chiou, Y.-H. Liu, K.-S. Kwan, Y.-J. Chen, Inorg. Chem. 48 (2009) 1857.

[23] J.B. Flanagan, S. Margel, A.J. Bard, F.C. Anson, J. Am. Chem. Soc. 100 (1978) 4248.

[24] F. Barrière, N. Camire, W.E. Geiger, U.T. Mueller-Westerhoff, R. Sanders, J. Am. Chem. Soc. 124 (2002) 7262

[25] D.M. D'Alessandro, F.R. Keene, Dalton Trans. (2004) 3950.

[26] F. Barrière, W.E. Geiger, J. Am. Chem. Soc. 128 (2006) 3980.

[27] M.E. Stoll, S.R. Lovelace, W.E. Geiger, H. Schimanke, I. Hyla-Kryspin, R. Gleiter, J. Am. Chem. Soc. 121 (1999) 9343.

[28] C.G. Atwood, W.E. Geiger, J. Am. Chem. Soc. 122 (2000) 5477.

[29] T. Ito, T. Hamaguchi, H. Nagino, T. Yamaguchi, H. Kido, I.S. Zavarine, T. Richmond, J. Washington, C.P. Kubiak, J. Am. Chem. Soc. 121 (1999) 4625

[30] D.-L. Sun, S.V. Rosokha, S.V. Lindeman, J.K. Kochi, J. Am. Chem. Soc. 125 (2003) 15950.

[31] M.-C. Chung, X. Gu, B.A. Etzenhouser, A.M. Spuches, P.T. Rye, S.K. Seetharaman, D.J. Rose, J. Zubieta, M.B. Sponsler, Organometallics 22 (2003) 3485.

[32] N.S. Hush, Prog. Inorg. Chem. 8 (1967) 391.

[33] K.Y. Wong, P.N. Schatz, Prog. Inorg. Chem. 28 (1981) 369.

[34] D. Oh, M. Sano, S.G. Boxer, J. Am. Chem. Soc. 113 (1991) 6880.

[35] G.U. Bublitz, W.M. Laidlaw, R.G. Denning, S.G. Boxer, J. Am. Chem. Soc. 120 (1998) 6068.

[36] T.P. Treynor, S.G. Boxer, J. Phys. Chem. A 108 (2004) 1764.

[37] P.H. Dinolfo, S.J. Lee, V. Coropceanu, J.-L. Brédas, J.T. Hupp, Inorg. Chem. 44 (2005) 5789.

[38] K. Lancaster, S.A. Odom, S.C. Jones, S. Thayumanavan, S.R. Marder, J.-L. Brédas, V. Coropceanu, S. Barlow, J. Am. Chem. Soc. 131 (2009) 1717.

[39] C.E.B. Evans, D. Ducharme, M.L. Naklicki, R.J. Crutchley, Inorg. Chem. 34 (1995) 1350.

[40] S.F. Nelsen, A.E. Konradsson, M.N. Weaver, J.P. Telo, J. Am. Chem. Soc. 125 (2003) 12493

[41] R.C. Johnson, J.T. Hupp, J. Am. Chem. Soc. 123 (2001) 2053.

[42] V. Cororpceanu, M. Malagoli, J.M. André, J.L. Brédas, J. Am. Chem. Soc. 124 (2002) 10519.

[43] A. Heckmann, C. Lambert, M. Goebel, R. Wortmann, Angew. Chem., Int. Ed. Engl. 43 (2004) 5851

[44] A. Heckmann, S. Amthor, C. Lambert, Chem. Commun. (2006) 2959.

[45] A. Heckmann, C. Lambert, J. Am. Chem. Soc. 129 (2007) 5515

[46] A.B.P. Lever, Notes on time frames, Comprehensive Organometallic Chemistry II, vol. 2, Elsevier, Amsterdam, 2003, pp. 435-438.

[47] R.R. Rocha, A.P. Shreeve, Inorg. Chem. 43 (2004) 2231.

[48] C.G. Atwood, W.E. Geiger, A.L. Rheingold, J. Am. Chem. Soc. 115 (1993) 5310.

[49] M.R. Torres, A. Vegas, A. Santos, J. Organomet. Chem. 309 (1986) 169.

[50] A.F. Hill, in: D.E. Shriver, M.I. Bruce (Eds.), Comprehensive Organometallic Chemistry II, vol. 7, Pergamon, Oxford, 1995, pp. 399-411.

[51] M.A. Esteruelas, H. Werner, J. Organomet. Chem. 303 (1986) 221

[52] H. Werner, U. Meyer, K. Peters, H.G. von Schnering, Chem. Ber, 122 (1989) 2089.

[53] S.H. Liu, Y. Chen, K.L. Wan, T.B. Wen, Z. Zhou, M.F. Lo, I.D. Williams, G. Jia, Organometallics 21 (2002) 4984.

[54] H. Xia, T.B. Wen, Q.Y. Hu, X. Wang, X. Chen, L.Y. Shek, I.D. Williams, K.S. Wong, G.K.L. Wong, G. Jia, Organometallics 24 (2005) 562.

[55] J.T. Poulton, M.P. Sigalas, O. Eisenstein, K.G. Caulton, Inorg. Chem. 32 (1993) 5490

[56] A.V. Marchenko, H. Gérard, O. Eisenstein, K.G. Caulton, N. J. Chem. 25 (2001) 1382

[57] A.V. Marchenko, H. Gérard, O. Eisenstein, K.G. Caulton, N. J. Chem. 25 (2001) 1244.

[58] F. Pevny, R.F. Winter, B. Sarkar, S. Záliš, Dalton Trans. (2010) 8000.

[59] S.K. Seetharaman, M.-C. Chung, U. Englich, K. Ruhlandt-Senge, M.B. Sponsler, Inorg. Chem. 46 (2007) 561.

[60] J. Maurer, M. Linseis, B. Sarkar, B. Sclıwederski, M. Niemeyer, W. Kaim, S. Záliš, C. Anson, M. Zabel, R.F. Winter, J. Am. Chem. Soc. 130 (2008) 259.

[61] X.H. Wu, S. Jin, J.H. Liang, Z. Yong, G.-A. Yu, S.H. Liu, Organometallics 28 (2009) 2450.

[62] S.-H. Choi, I. Bytheway, Z. Lin, G. Jia, Organometallics 17 (1998) 3974.

[63] X. Wu, T. Weng, S. Jin, J. Liang, R. Guo, G.-A. Yu, S.H. Liu, J. Organomet. Chem. 694 (2009) 1877.

[64] S. Záliš, R.F. Winter, W. Kaim, Coord. Chem. Rev. 254 (2010) 1383

[65] R.F. Winter, F.M. Hornung, Organometallics 18 (1999) 4005.

[66] N. Gauthier, N. Tchouar, F. Justaud, G. Argouarch, M.P. Cifuentes, L. Toupet, D. Touchard, J.-F. Halet, S. Rigaut, M.G. Humphrey, K. Costuas, F. Paul, Organometallics 28 (2009) 2253.

[67] F. Paul, B.G. Ellis, M.I. Bruce, L. Toupet, T. Roisnel, K. Costuas, J.-F. Halet, C. Lapinte, Organometallics 25 (2006) 649.
[68] C.K. Jørgensen, Coord. Chem. Rev, 1 (1966) 164

[69] M.D. Ward, J.A. McCleverty, Dalton Trans. (2002) 275

[70] S.J. Sherlock, D.C. Boyd, B. Moasser, W.L. Gladfelter, Inorg. Chem. 20 (1991) 3626 .

[71] M. Deussen, H. Bässler, Chem. Phys. 164 (1992) 247.

[72] H. Bässler, M. Deußen, S. Heun, U. Lemmer, R.F. Mahrt, Z. Phys. Chem. 184 (1994) 233.

[73] J. Maurer, Präparative, elektrochemische, spektroelektrochemische und quantenchemische Studien an Ruthenium-Vinylkomplexen: "Schuldiges" Verhalten in Organometallverbindungen, Logos Verlag Berlin GmbH, Berlin, 2007.

[74] J. Maurer, B. Sarkar, B. Schwederski, W. Kaim, R.F. Winter, S. Záliš, Organometallics 25 (2006) 3701.

[75] M.C.B. Colbert, J. Lewis, N.J. Long, P.R. Raithby, M. Younus, A.J.P. White, D.J. Williams, N.N. Payne, L. Yellowlees, D. Beljonne, N. Chawdhury, R.H. Friend, Organometallics 17 (1998) 3034.

[76] M.A. Fox, R.L. Roberts, W.M. Khairul, F. Hartl, P.J. Low, J. Organomet. Chem. 692 (2007) 3277.

[77] D.J. Armitt, M.I. Bruce, M. Gaudio, N.N. Zaitseva, B.W. Skelton, A.H. White, B. Le Guennic, J.-F. Halet, M.A. Fox, R.L. Roberts, F. Hartl, P.J. Low, Dalton Trans. (2008) 6763 .

[78] M.A. Fox, J.D. Farmer, R.L. Roberts, M.G. Humphrey, P.J. Low, Organometallics 28 (2009) 5266

[79] C. Olivier, B. Kim, D. Touchard, S. Rigaut, Organometallics 27 (2008) 509.

[80] S.F. Nelsen, A.E. Konradsson, J.P. Telo, J. Am. Chem. Soc. 127 (2005) 920

[81] A. Wartini, H.A. Staab, F.A. Neugebauer, Eur. J. Org. Chem. (1998) 1161.

[82] A. Wartini, J. Valenzuela, H.A. Staab, F.A. Neugebauer, Eur. J. Org. Chem. (1998) 139.

[83] D.R. Kattnig, B. Mladenova, G. Grampp, C. Kaiser, A. Heckınann, C. Lambert, J. Phys. Chem. C 113 (2009) 2983.

[84] M. Carano, M. Careri, F. Cicogna, I. D’Ambra, J.L. Houben, G. Ingrosso, M. Marcaccio, F. Paolucci, C. Pinzino, S. Roffia, Organometallics 20 (2001) 3478

[85] M. Carano, F. Cicogna, I. D’Ambra, B. Gaddi, G. Ingrosso, M. Maracaccio, D. Paolucci, F. Paolucci, C. Pinzino, S. Roffia, Organometallics 21 (2002) 5583.

[86] S.V. Lindemann, S.V. Rosokha, J.K. Kochi, J. Am. Chem. Soc. 124 (2002) 843

[87] S. Roué, C. Lapinte, T. Bataille, Organometallics 23 (2004) 2558.

[88] C. Elschenbroich, J. Plackmeyer, M. Nowotny, A. Behrendt, K. Harms, J. Pebler, O. Burghaus, Chem. Eur. J. 11 (2005) 7427.

[89] P. Mücke, M. Zabel, R. Edge, D. Collison, S. Clément, S. Záliš, R.F. Winter, J. Organomet. Chem. in press.

[90] K. Kowalski, M. Linseis, R.F. Winter, M. Zabel, S. Záliš, H. Kelın, H.-J. Krüger, B. Sarkar, W. Kaim, Organometallics 28 (2009) 4196.

[91] R. Prins, A.R. Korswagen, J. Organomet. Chem. 25 (1970) C74.

[92] J.A. Kramer, D.N. Hendrickson, Inorg. Chem. 19 (1980) 3330

[93] H.P. Fritz, Infrared and raman spectral studies of $\pi$-complexes formed between metals and $\mathrm{C}_{n} \mathrm{H}_{n}$ rings, in: F.G.A. Stone, R. West (Eds.), Advances in Organometallic Chemistry, vol. 1, Academic Press, New York, 1964, pp. 239316.

[94] D.N. Hendrickson, S.M. Oh, T.-Y. Dong, T. Kambara, M.J. Cohn, M.F. Moore, Comm. Inorg. Chem. 4 (1985) 329.

[95] T.Y. Dong, C.-H. Huang, C.-K. Chang, H.-S. Hsieh, S.-M. Peng, G.-H. Lee Organometallics 14 (1995) 1776.

[96] R. Webb, P.M. Hagen, R.J. Wittebort, M. Sorai, D.N. Hendrickson, Inorg. Chem. $31(1992) 1791$

[97] T. Kambara, D.N. Hendrickson, T.-Y. Dong, M.J. Cohn, J. Am. Chem. Soc. 86 (1987) 2362.

[98] M. Kai, M. Katada, H. Sano, Chem. Lett. 18 (1989) 1473.

[99] T.-Y. Dong, D.N. Hendrickson, C.G. Pierpont, M.F. Moore, J. Am. Chem. Soc. 108 (1986) 963.

[100] T.-Y. Dong, T. Kambara, D.N. Hendrickson, J. Am. Chem. Soc. 108 (1986) 4423

[101] T.-Y. Dong, T. Kambara, D.N. Hendrickson, J. Am. Chem. Soc. 108 (1986) 5857.

[102] O. Lavastre, J. Plass, P. Bachmann, S. Guesmi, C. Moinet, P.H. Dixneuf, Organometallics 16 (1997) 184.

[103] S.C.-F. Lam, V.W.-W. Yam, K.M.-C. Wong, E.C.-C. Cheng, N. Zhu, Organometallics 24 (2005) 4298.

[104] K.M.-C. Wong, S.C.-F. Lam, C.-C. Ko, N. Zhu, V.W.-W. Yam, S. Roué, C. Lapinte, S. Fathallah, K. Costuas, S. Kahlal, J.-F. Halet, Inorg. Chem. 42 (2003) 7086.

[105] H. Jiao, K. Costuas, J.A. Gladysz, J.-F. Halet, M. Guillemot, L. Toupet, F. Paul, C Lapinte, J. Am. Chem. Soc. 125 (2003) 9511.

[106] N. Gauthier, C. Olivier, S. Rigaut, D. Touchard, T. Roisnel, M.G. Humphrey, F. Paul, Organometallics 27 (2008) 1063.

[107] A. Klein, O. Lavastre, J. Fiedler, Organometallics 25 (2006) 635

[108] F. Pevny, E. Di Piazza, L. Norel, M. Drescher, R.F. Winter, S. Rigaut, Organometallics 29 (2010) 5912. 